U.S. DEPARTMENT OF COMMERCE / National Bureau of Standards

\title{
The Characteristics of Iris-Fed Millimeterwave Rectangular Microstrip Patch Antennas
}




\section{NATIONAL BUREAU OF STANDARDS}

The National Bureau of Standards' was established by an act of Congress on March 3, 1901. The Bureau's overall goal is to strengthen and advance the Nation's science and technology and facilitate their effective application for public benefit. To this end, the Bureau conducts research and provides: (1) a basis for the Nation's physical measurement system, (2) scientitic and technological services for industry and government, (3) a technical basis for equity in trade, and (4) technical services to promote public safety. The Bureau's technical work is performed by the National Measurement Laboratory, the National Engineering Laboratory, and the Institute for Computer Sciences and Technology.

THE NATIONAL MEASUREMENT LABORATORY provides the national system of physical and chemical and materials measurement; coordinates the system with measurement systems of other nations and furnishes essential services leading to accurate and uniform physical and chemical measurement throughout the Nation's scientific community, industry, and commerce; conducts materials research leading to improved methods of measurement, standards, and data on the properties of materials needed by industry, commerce, educational institutions, and Government; provides advisory and research services to other Government agencies; develops, produces, and distributes Standard Reference Materials; and provides calibration services. The Laboratory consists of the following centers:

\section{Absolute Physical Quantities ${ }^{2}$ - Radiation Research - Chemical Physics - Analytical Chemistry - Materials Science}

THE NATIONAL ENGINEERING LABORATORY provides technology and technical services to the public and private sectors to address national needs and to solve national problems; conducts research in engineering and applied science in support of these efforts; builds and maintains competence in the necessary disciplines required to carry out this research and technical service; develops engineering data and measurement capabilities; provides engineering measurement traceability services; develops test methods and proposes engineering standards and code changes; develops and proposes new engineering practices; and develops and improves mechanisms to transfer results of its research to the ultimate user. The Laboratory consists of the following centers:

Applied Mathematics - Electronics and Electrical Engineering ${ }^{2}$ - Manufacturing Engineering - Building Technology - Fire Research - Chemical Engineering ${ }^{2}$

THE INSTITUTE FOR COMPUTER SCIENCES AND TECHNOLOGY conducts research and provides scientific and technical services to aid Federal agencies in the selection, acquisition, application, and use of computer technology to improve effectiveness and economy in Government operations in accordance with Public Law 89-306 (40 U.S.C. 759), relevant Executive Orders, and other directives; carries out this mission by managing the Federal Information Processing Standards Program, developing Federal ADP standards guidelines, and managing Federal participation in ADP voluntary standardization activities; provides scientific and technological advisory services and assistance to Federal agencies; and provides the technical foundation for computer-related policies of the Federal Government. The Institute consists of the following centers:

Programming Science and Technology-Computer Systems Engineering.

'Headquarters and Laboratories at Gaithersburg, MD, unless otherwise noted; mailing address Washington, DC 20234.

${ }^{2}$ Some divisions within the center are located at Boulder, CO 80303. 


\section{The Characteristics of Iris-Fed Millimeterwave Rectangular Microstrip Patch Antennas

D. H. Greenlee

M. Kanda

Electromagnetic Fields Division National Engineering Laboratory National Bureau of Standards U.S. Department of Commerce Boulder, Colorado 80303

D. C. Chang

Department of Electrical Engineering University of Colorado

Boulder, Colorado 80309

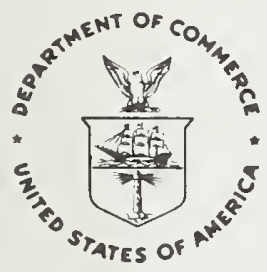

U.S. DEPARTMENT OF COMMERCE, Malcolm Baldrige, Secretary

NATIONAL BUREAU OF STANDARDS, Ernest Ambler, Director 
National Bureau of Standards Technical Note 1063

Natl. Bur. Stand. (U.S.), Tech. Note 1063, 50 pages (Oct. 1983) CODEN: NBTNAE

U.S. GOVERNMENT PRINTING OFFICE

WASHINGTON: 1983

For sale by the Superintendent of Documents, U.S. Government Printing Office, Washington, DC 20402

Price $\$ 4.00$

(Add 25 percent for other than U.S. mailing) 


\section{CONTENTS}

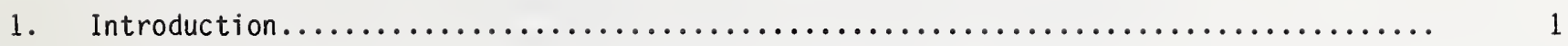

2. A Model of the Iris-Fed Rectangular Microstrip Patch Antenna................. 2

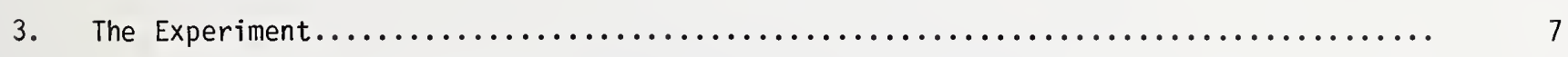

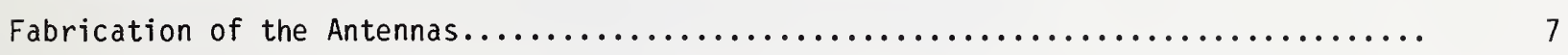

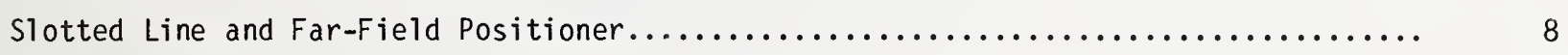

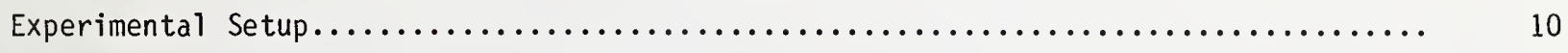

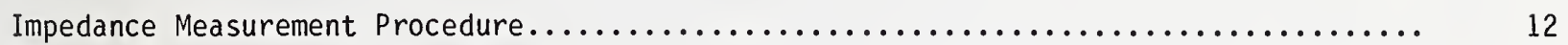

4. Experimental Results........................................ 12

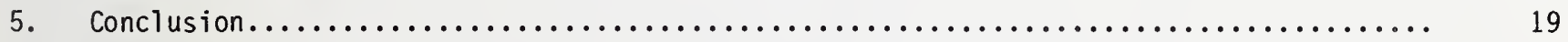

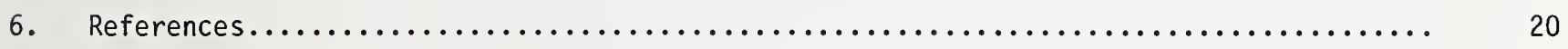

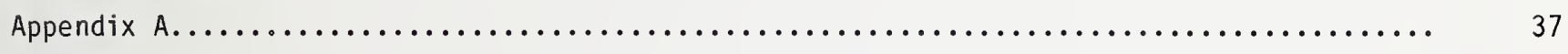

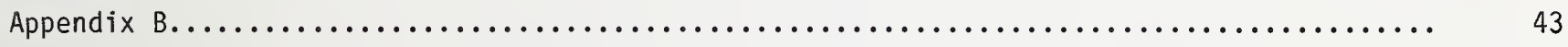





\title{
THE CHARACTERISTICS OF IRIS-FED MILLIMETERHAVE RECTANGULAR MICROSTRIP PATCH ANTENNAS
}

\author{
D. H. Greenlee, M. Kanda, and D. C. Chang ${ }^{\dagger}$ \\ Electromagnetic Fields Division \\ National Bureau of Standards \\ Boulder, Colorado 80303
}

The fabrication of various iris-fed millimeterwave rectangular microstrip patch antennas is described. A model is proposed to describe the iris-fed antenna. Irises ranging in size from 15 percent of the area of the patch to the fully open waveguide are used to couple energy into the antenna. Resonance of the antenna is observed to be insensitive to the size of the iris for irises up to 115 percent of the size of the patch. A study is also made of the relationship of coupling to the antenna as a function of position of the iris with respect to the transverse plane of the waveguide, the iris always being centered with respect to the patch. In general, the antenna has a VSWR in the waveguide feed on the order of $5: 1$ at resonance, except for the fully open waveguide which gives rise to a VSWR of 2.9:1 at resonance. Far-field antenna power patterns are observed to be quite broad with $\mathrm{H}-\mathrm{pl}$ ane beamwidths on the order of $130^{\circ}$. Maximum antenna gain is seen to be $4.5 \mathrm{dBi}$ with $3 \mathrm{dBi}$ typical. An initial study is made of the microstrip patch antenna fed from a longitudinal waveguide wall. Results indicate that this feed structure is likely to prove valuable for microstrip patch antennas with coupling at least as good as for the transverse-fed patch added to the possibility of feeding of multiple patches from a single waveguide.

Key words: antenna gain; aperture coupling; cavity; half-power beamwidth; iris; microstrip; millimeterwave; patch antenna; power pattern.

\section{Introduction}

Over the past several years the importance of the millimeterwave spectrum has grown markedly. Systems requiring extremely broadband transmission and secure communications, and a wide variety of radar applications are responsible for the growth in utilization of these extremely high radio frequencies. To utilize this portion of the spectrum efficiently, appropriate antennas are a natural requirement. The versatility of the microstrip patch antenna at microwave frequencies suggests a potential usefulness at millimeterwaves. Low cost, ease of reproduction, ruggedness, light weight, and low profile are among the advantages this class of antennas offers at any frequency, including millimeterwaves.

However, it has become apparent that feed structures which operate quite well at microwave frequencies are not viable with millimeterwaves. Losses become significant in microstrip lines and coaxial feed components are not available above about $50 \mathrm{GHz}$. For that reason, it is desirable to investigate a new feed for the microstrip patch antennas useful at millimeter wavelengths: the iris feed. In this structure, a small hole is opened in the metallic ground plane, and energy is coupled through that iris into the antenna.

\footnotetext{
†Department of Electrical Engineering, University of Colorado, Boulder, Colorado 80309.
} 
The purpose of this report is to discuss briefly the model relevant to the microstrip patch antenna and to present experimental results for iris-fed millimeterwave rectangular microstrip patch antennas. Work was done at millimeter wavelengths rather than scaled to lower frequencies. This made some aspects of the work much easier due to the small component sizes. Yet further reductions in antenna size would have introduced severe tolerance problems related to fabrication and alignment of the antennas. Also, the high frequencies made procurement of proper test equiment and sources difficult.

\section{A Model of the Iris-Fed Rectangular Microstrip Patch Antenna}

A microstrip device is a three-layer device consisting of a dielectric substrate sandwiched between two layers of conducting material. Copper-teflon-copper and copper-alumina-copper sandwiches are commonly used in practice. In figure 1 a rectangular microstrip patch antenna is illustrated. Reference will be made throughout this report to the dimensions and coordinate system of that drawing.

Feed effects of the microstrip patch antenna used typically at microwave frequencies are based on a traditional coaxial probe or microstrip line feed to the antenna. The present experiment, however, has been done on microstrip patch antennas with an iris feed through the ground plane. Clearly there are similarities in basic assumptions and final results, particularly for the far-field pattern and dominant mode effects, if the iris is small. But certain parameters will be radically different for the iris-fed case, particularly the input impedance of the antenna.

One simple approach to modeling the iris-fed patch antenna is illustrated in figure 2 . In this analysis the iris is treated as a window in the waveguide; the window is capacitive, inductive, or resonant depending upon the geometry. The feed susceptance, $B_{f}$, is described by a simple reactive element. For a rectangular iris centered with respect to a transverse plane of the waveguide, as in figure 3 , the normalized susceptance is given by [1],

$$
\begin{gathered}
B_{f}=-\left(\lambda_{g} / a\right) \cot ^{2}(\pi D / 2 a)+\frac{\pi\left(a^{2}-D^{2}\right)}{4 a D \cos (\pi D / 2 a)} x \\
\frac{\left(1-\lambda_{0}^{2} / 4 D^{2}\right)}{\left(1-\lambda_{0}^{2} / 4 a^{2}\right)} \frac{4 b d}{\lambda_{g} a} \ln \csc (\pi d / 2 b)+\left(\lambda_{g} / a D^{2}\right) x \\
\frac{b^{2}}{3}+\frac{d^{2}}{2}-\frac{8 b d}{2}-\frac{2 b^{2}}{\pi^{2}} \sum_{n=1}^{\infty}(n \pi d / b) K[2 n \pi(a-d) / b] / n^{2} \\
K(v)=\int_{v}^{\infty} d w \int_{W}^{\infty} K_{0}(u) d u \cong e^{-v}(1+2 v / \pi)^{-1 / 2}
\end{gathered}
$$

The admittance due to the unloaded patch is then described by the patch conductance and susceptance, $G_{p}$ and $B_{p}$.

A deeper investigation, however, indicates that one cannot simply describe the iris as one susceptive element and the patch as another susceptive-conductive element acting independently. The iris will cause the excitation of higher-order modes both in the waveguide which feeds the antenna and in the cavity-like region under the patch. These modes will not be the same as those excited by an isolated identical iris in a transverse plane of a very long section of waveguide. Furthermore, the 
cavity behavior of the patch and substrate will be disrupted if the iris is very large at all, a factor not well accounted for by this model.

A more rigorous formulation of the problem is made by treating the antenna as a radiating cavity, as in the cavity and modal expansion models [2,3], but with energy coupled into the cavity through an aperture. The antenna and feed are then modeled as in figure 4 with the sources far to the left. To represent the fields in the aperture, an equivalent magnetic current $\bar{M}_{S}=\bar{n} \times \bar{E}_{t}^{a}$ is assumed on the closed cavity wall and its negative on the closed waveguide aperture. Beginning with a formula based on the conservation of reaction over the iris [4],

$$
\iint_{A}\left(\left(\bar{E}_{t}^{\mathrm{a}} \times \bar{H}^{\mathrm{a}}\right) \cdot \overline{\mathrm{ds}}\right)_{\text {guide }}=\iint_{A}\left(\left(\bar{E}_{t}^{\mathrm{a}} \times \bar{H}^{\mathrm{a}}\right) \cdot \overline{\mathrm{ds}}\right)_{\text {cavity }},
$$

where the $\bar{E}_{t}^{a}$ are tangential electric fields in the aperture and the $\bar{H}^{\mathrm{a}}$ are the aperture magnetic fields, it can be shown that the normalized dominant mode admittance looking into the aperture is

$$
\frac{Y_{i n}}{Y_{10}}=j B_{g}+\frac{n^{2}}{Y_{10}} \quad\left[j B_{c}-j \frac{\omega\left(b_{10} / V\right)^{2}}{\omega^{2}-\omega_{10}^{2}}\right],
$$

where

$$
B_{g}=-j \sum_{m n \neq 10} \frac{Y_{m n}}{Y_{10}} \frac{V_{m n}}{V_{10}}
$$

is the shunt susceptance due to the waveguide side of the aperture,

$$
B_{C}=-\frac{\omega}{V^{2}} \underset{m n \neq 10}{\sum} \frac{b_{m n}^{2}}{\omega^{2}-\omega_{m n}^{2}} \text {, }
$$

is the shunt susceptance due to all higher order cavity modes,

$$
b_{m n}=\iint_{A}\left(\bar{E}_{t}^{a} \times \bar{h}_{m n}\right) \cdot d S
$$

where $\bar{h}_{m n}$ are the magnetic mode vectors, and, for mode index, $m n, \gamma_{m n}$ are the characteristic wave admittances and $V_{m n}$ the corresponding mode voltages in the waveguide is $V_{10}=E_{10}(a b / 2)^{1 / 2}$ where $E_{10}$ is the dominant model amplitude and $a b$ is the waveguide cross-sectional area. By the boundary conditions at the aperture the related cavity voltage $V$ and $n=V / V_{10}$ can be found. (In using eq (3) $V$ need never be calculated, however, since it cancels in every term due to the normalization.)

The final term of eq (3) accounts for the dominant mode of the antenna. The antenna is said to be resonant when this term is purely real. Of course the input susceptance of the antenna will most likely not be zero at the resonant frequency due to the susceptance of the higher order modes, represented by $\mathrm{B}_{\mathrm{g}}$ and $\mathrm{B}_{\mathrm{C}}$ in figure 4 . A discussion of the way in which the resonant frequency can be experimentally determined is presented in a later chapter. 
The expression for $\mathrm{B}_{\mathrm{g}}$ was obtained from a variational solution for the susceptance of an aperture in the junction of two waveguides. That susceptance can be well approximated [4] by one half of the susceptance of a similar aperture in a long section of the first waveguide plus one half of the susceptance due to the aperture in a long section of the second waveguide. Correspondingly, $B_{g}$ can be approximated by one half of the susceptance of the waveguide-antenna aperture if that aperture were located in a long section of the waveguide.

The $b_{m n}$ are determined by appropriate choice of $\bar{E}_{t}^{a}$ and by using the formulas,

$$
\begin{aligned}
\bar{h}_{m n}(x, y)=\frac{1}{j \omega \mu} & {\left[\bar{a}_{x} k_{n} \cos \left(k_{m} x\right) \sin \left(k_{n} y\right)+\right.} \\
& \left.-\bar{a}_{y} k_{m} \sin \left(k_{m} x\right) \cos \left(k_{n} y\right)\right]
\end{aligned}
$$

The resonant radian frequencies $\omega_{m n}$, are well-approximated by

$$
k_{m n}^{2}=w_{m n}^{2} \sqrt{\mu \varepsilon}=k_{m}^{2}+k_{n}^{2}
$$

with $k_{m}=m_{\pi} / h$ and $k_{n}=n_{\pi} / l$ except for the dominant mode. In that case, $k_{10}$ must be determined.

For the radiating antenna, the eigenvalues $k_{m}$ and $k_{n}$ take on complex values of magnitude slightly less than $m \pi / h$ and $n \pi / l$ but are very well approximated by these values for the non-radiating cavity. The one exception is $k_{10}$, which has a value of magnitude 96 percent to 98 percent of $\pi / h$. The method by which $k_{10}$ may be found is described below [2].

$$
\begin{aligned}
& \tan \left(k_{10} h\right)=\frac{2 k_{10}{ }^{\alpha} 10}{k_{10}^{2}-\alpha_{10}^{2}} \\
& \alpha_{10}=j \frac{2 \pi Z}{\lambda_{0}} \frac{t}{l} Y_{W} \\
& Y_{W}=\text { radiating wall admittance at } x=0, h .
\end{aligned}
$$

The solution of eq (9) is found iteratively from the first two terms of a Taylor series expansion about $\pi$ :

$$
\begin{gathered}
k_{10}=(\pi / h)-\left(\Delta_{q} / h\right) \\
\Delta_{p+1}=\frac{2\left(\alpha_{10} h\right)\left(\pi-\Delta_{p}\right)}{\left(\alpha_{10} h\right)^{2}+2 \Delta_{p} \pi-\Delta_{p}^{2}-\pi^{2}}-\frac{\Delta_{p}^{3}}{3}
\end{gathered}
$$

A sufficiently accurate approximation of $k_{10}$ usually found by taking four iterations, that is, $q=$ 4. The impedance boundary condition has little effect on the higher order wave numbers which are well approximated by $k_{m n}^{2}=(m \pi / h)^{2}+(n \pi / l)^{2}, m n \neq 10$.

Lacking a rigorous solution for the wall admittance, one approximates $G_{W}$ to be the conductance of a TEM wave radiating into half-space from a narrow parallel plate waveguide of width \& [4]. The wall 
susceptance is approximated by the capacitance of an open microstrip circuit. The resulting equations for the wall admittance of the rectangular microstrip patch are:

$$
\begin{gathered}
G_{W}=\frac{\pi l}{Z_{0} \lambda_{0}} \\
B_{W}=0.01668 \frac{\Delta l}{t} \frac{\ell}{\lambda_{0}} \varepsilon_{e} \\
Z_{0}=377 \Omega
\end{gathered}
$$

where $\Delta l / t$ is Hammerstad's length extension formula for a microstrip transmission line [5] and $\varepsilon_{e}$ is Schneider's effective dielectric constant for microstrip [6]

$$
\begin{aligned}
& \frac{\Delta \ell}{t}=0.412 \frac{\varepsilon_{r}+0.300}{\varepsilon_{r}-0.258} \frac{\frac{\ell}{t}+0.262}{\frac{\ell}{t}+0.813} \\
& \varepsilon_{e}=\frac{\varepsilon_{r}+1}{2}+\frac{\varepsilon_{r}-1}{2}\left[1+\frac{10 t}{\ell}\right]^{-1 / 2}
\end{aligned}
$$

Further insight into the coupling mechanism of the antenna is gained by considering both the magnetic and electric dipole moments of the iris. Excitation of a z-directed E field in the cavity will be due to a magnetic dipole moment co-planar with the aperture and due to an electric dipole moment normal to the aperture [7]. If the aperture is very small the guide field pattern near the aperture plane will be very close to that for a short-circuited waveguide with field components described by

$$
\begin{gathered}
E_{y}=E_{10} \sin \frac{\pi x^{\prime \prime}}{a} \sin \frac{2 \pi z^{\prime \prime}}{\lambda_{g}} \\
H_{x}=-j \frac{E_{10}}{Z_{10}} \sin \frac{\pi x^{\prime \prime}}{a} \cos \frac{2 \pi z^{\prime \prime}}{\lambda_{g}} \\
H_{z}=j \frac{E_{10}}{Z_{10}} \frac{\lambda g}{2 a} \cos \frac{\pi x^{\prime \prime}}{a} \sin \frac{2 \pi z^{\prime \prime}}{\lambda_{g}} .
\end{gathered}
$$

For a very small iris, then, neither tangential electric fields nor normal magnetic fields will exist in the aperture plane. Instead, one would expect only an x-directed magnetic field.

As the iris becomes larger both the magnetic and electric fields will have greater and greater fringing effects. One would expect that some of the electric field lines would bend around normal to the aperture plane and that an electric field tangent to the aperture plane would exist across the iris.

Coupling into the z-directed electric fields of the cavity by $\bar{p}_{n}$, the electric dipole normal to the aperture, will be small. Rather, the stronger coupling mechanism is that due to the transverse 
magnetic dipole, $\bar{M}_{t}$, co-planar with the aperture. In the nearly short-circuited waveguide case, a magnetic field, or its equivalent magnetic current, $j_{m}$, exists in the aperture plane. The transverse magnetic dipole is proportional to $\bar{j}_{m}$ and co-directional with it. It is also a function of the iris geometry which determines the magnetic polarizability of the aperture. Excitation of $E_{z}$ under the patch due to $\bar{M}_{t}$ will be maximized when $x^{\prime \prime}=a / 2$, that is, when the iris is centered with respect to the $x$ coordinate of the waveguide opening. Given the shape of the iris, the magnetic polarizability (a dyadic), $\bar{\alpha}_{m}$, can be determined. The magnetic dipole in the aperture is then [7]

$$
\bar{M}_{t}=\bar{\alpha}_{m} \cdot \bar{H}^{a} .
$$

This will be maximized, according to eq (19), when $x^{\prime \prime}=a / 2$.

\section{Calculation of the Far-field Pattern}

When the iris is small with respect to the size of the patch, the radiation pattern can be well calculated. However, as the iris becomes larger, radiation from the iris itself will become significant.

Calculation of the radiation pattern of the antenna including the iris effects can be made by considering a radiating aperture in the plane of the patch. The fields in this aperture are the superposition of the fringing fields at the radiating edges of the patch and the fields due to radiation from the iris. This total field in the aperture can be described by $F\left(x^{\prime}, y^{\prime}, 0\right)=A\left(x^{\prime}\right.$, $\left.y^{\prime}, 0\right) \exp \left[-j \psi\left(x^{\prime}, y^{\prime}, 0\right)\right]$ where the functions $A$ and $\psi$ describe the amplitude and phase of the aperture field. The far-field radiation pattern due to this aperture field can be shown to be [6]

$$
U(\theta, \phi)=\frac{j}{2 \lambda_{0}} \frac{e^{-j k r}}{r} \iint_{A} F\left(x^{\prime}, y^{\prime}, 0\right)\left(\cos \theta+\bar{a}_{z} \cdot \bar{s}\right) e^{j k \sin \theta\left(x^{\prime} \cos \phi+y^{\prime} \sin \phi\right)} d x^{\prime} d y^{\prime}
$$

where

$$
\begin{aligned}
& r=\text { distance from source point to test point } \\
& \bar{s}=\bar{a}_{x} s_{x}+\bar{a}_{y} s_{y}+\bar{a}_{z} s_{z} \\
& s_{x}=\frac{1}{k} \frac{\delta \Psi}{\delta x}
\end{aligned}
$$

and

$$
\begin{aligned}
& s_{y}=\frac{1}{k} \frac{\delta \Psi}{\delta y} \\
& s_{z}=\left(1-s_{x}^{2}-s_{y}^{2}\right)^{1 / 2} .
\end{aligned}
$$


Given an aperture distribution $F\left(x^{\prime}, y^{\prime}, 0\right)$ the radiated field pattern can be calculated from eq (21). For a large iris this function is likely to be rather complicated. For a small iris, it will reduce to the aperture distribution of a uniform electric field oriented in the $y$-direction.

\section{The Experiment}

Fabrication of the Antennas

Fabrication of the microstrip patch antennas used in this project involved both design, including choice of the antenna material, and actual fabrication. Because the dielectric constant of the substrate, $\varepsilon_{r}$, is the most critical parameter with respect to materials used, its value was selected with care. The tolerance given for the specified value of $\varepsilon_{r}$ was of great importance since a small tolerance-related change in $\varepsilon_{r}$ from the value used in the design would cause a significant error in the antenna resonant frequency as compared to the predicted value. Pertinent characteristics of these materials are presented in table 1.

Table 1. Antenna materials characteristics

$\begin{array}{cc}\text { Material } & \varepsilon_{r}=2.20 \pm 0.02 \\ \text { Copper cladding } & 157.5 \mathrm{~g} / \mathrm{m}^{2} \\ \text { thickness } & 71 \times 10^{-6} \mathrm{~m} \\ \text { tan } \delta & 0.001 \\ \text { Thickness }(t) & 0.127 \pm 3 \% \mathrm{~mm} \\ \text { Substrate material } & \text { Random glass } \\ & \text { fiber PTFE }\end{array}$

$\varepsilon_{r}=10.5 \pm 0.25$

$39.38 \mathrm{~g} / \mathrm{m}^{2}$

$18 \times 10^{-6} \mathrm{~m}$

0.0015

$0.127 \pm 3 \% \mathrm{~mm}$

Random glass

fiber PTFE

Once the desired patch size for operation at a resonant frequency in the 60 to $65 \mathrm{GHz}$ range was determined, the antenna was photolithographically fabricated. The first step of this process was that of forming the exposure masks. Glass plates bearing the image of the patch were then created by exposure in a pattern generator contolled by this tape. The plates were subsequently developed in a process similar to that used for black and white photographs.

After the copper surfaces of the antenna material was cleaned, the side to be etched was coated with photoresist. Positive or negative process resists were used as needed, depending upon whether the glass plates had been developed to bear a negative or a positive image of the patch. After appropriate baking to dry the photoresist and to ensure adhesion to the copper, the material was exposed to ultraviolet light while masked by the glass plate. Those areas of negative process photoresist exposed to the ultraviolet light underwent a chemical change so that, on application of the developer, a hard polymer formed. Unexposed photoresist was then rinsed away by a solvent. The 
opposite photochemical reaction occurred in the case of the positive photoresist with the unexposed region being the portion polymerized on development.

The antenna material was again baked after exposure and development to ensure proper adhesion of the protective photoresist to the copper. Etching was accomplished in a hot bath of moderately concentrated ferric chloride, removing all but the desired copper. The patch was then cleansed of the polymerized photoresist in a stripping solution, leaving only the clean copper patch.

The iris feed for the antenna was fabricated in a manner similar to that for the patch. The process used was negative to that of the patch so as to etch only a small, controlled amount of copper from the ground plane. Alignment of the iris with the patch was facilitated by special marks generated on both the patch and iris masks. When these marks were in proper alignment, as viewed under a microscope, the plates were taped together with the antenna sandwiched between them.

For the present purposes this process proved satisfactory in providing good iris-patch alignment. In every case studied the iris was centered with respect to the patch. The position of the center of the iris with respect to a target point on the patch was estimated to be within \pm 0.1 $\mathrm{mm}$, that is, within one tenth of the smallest dimension of the smallest iris used. For studies where even more precision is required in positioning of the iris, an apparatus enabling simultaneous microscopic mechanical alignment of the two masks and the antenna material would be preferable.

Slotted Line and Far-Field Positioner

Beyond fabrication of the antennas, construction of two major pieces of equipment was required: a slotted line for impedance measurements and a spherical far-field positioner for determination of the antenna radiation patterns. Drawings of these two devices are included in appendix $A$.

The slotted line consisted of a section of WR 12 waveguide $(3.78 \times 1.89 \mathrm{~mm}$, inside dimensions) mounted in a brass baseplate and a micrometer-and-spring driven probe assembly, scaled in $0.01 \mathrm{~mm}$ increments, which traveled along a dovetail track in the baseplate. The slot itself was $20 \mathrm{~mm} 1 \mathrm{ong}$ and was tapered at both ends to minimize slot radiation and generation of spurious modes. This slot length was equivalent to $3.2 \lambda_{\mathrm{g}}$ at $50 \mathrm{GHz}$ and $4.9 \lambda_{\mathrm{g}}$ at $75 \mathrm{GHz}$, where $\lambda_{\mathrm{g}}$ is the guide wavelength.

The $0.38 \mathrm{~mm}$-wide slot was formed by first milling away the upper wall of the waveguide and portions of the baseplate in which it was imbedded. Two very flat plates were then cut to fit into this milled-out region with their line of contact directly above the center line of the waveguide. These plates were then machined along that line of contact in such a way that, on affixing them again to the baseplate, a light gap occurred between them, thus forming the slot. This procedure was not only necessitated by the small ratio of slot width to waveguide wall thickness but also added versatility to the device by facilitating any future modification to the slot.

The electric-fieid probe excited a pick-up waveguide mounted on the upper traveling probe assembly. The signal in this section of waveguide was then detected to determine the field strength as a function of probe position.

The probe itself consisted of a $0.25-\mathrm{mm}$ diameter piece of phosphor-bronze wire. One end of the probe was forced into a short rod of plastic with the other end protruding $6.5 \mathrm{~mm}$ from the end of the rod. The plastic was in turn held in a screw-like device used to move the probe in and out of the slotted line and pick-up waveguide assembly. Vertical positioning of the probe was controlled by the 15-turns-per-cm (40-turns-per-inch) probe screw mount, thus giving better than 0.05-mm vertical position control. 
With the best short circuit available terminating the waveguide, a copper plate clamped tightly to the load end of the slotted line, VSWR of the short was measured to be $20: 1$ or higher across the frequency range of operation. Similarly, the measured guide wavelength was determined to be within $0.02 \mathrm{~mm}$ of the calculated guide wavelength, or within 0.4 percent, for all frequencies used. Considering the difficulties involved in millimeterwave measurements and compared to the range of values to be measured in the course of the experiment, it was decided that the slotted line had been well constructed for the purpose at hand.

For measurements of the far-field antenna power patterns, a spherical positioner was designed and constructed. Whereas the short wavelengths for which it was designed allowed the positioner to occupy only a very small space, the mechanical tolerances of construction and operation of the positioner precluded the accurate measurement of phase.

A commonly used constraint for antenna far-field measurements is that [9]

$$
2 D^{2} / \lambda<R
$$

$D=$ maximum antenna aperture dimension

$R=$ separation between transmitting and receiving antennas.

This formula, the aperture sizes of the antennas likely to be tested and used as standard receiving antennas, and the construction materials available were specifically considered in design of the positioner.

The base of the positioner consisted of a 1.2-m diameter ring cut from $2.54 \mathrm{~cm}$ thick plywood. This ring was cut by a band saw while the whole piece was turned on a milling machine table. Before cutting out the center section, a $1.3-\mathrm{cm}$ deep groove was scribed and milled out of the base providing a track for azimuthal variation of the positioner.

The upright moving arm was a semicircular arc of 2.54-cm-thick plywood cut in the same way as was the base. This arm was mounted offset from center on plastic feet designed both to travel freely in the azimuthal positioning track and simultaneously to maintain accurate control of the arm's position. A semicircular horizontal brace also mounted on plastic feet designed to track in the base azimuthal positioning groove, and a vertical brace, held the upright arm perpendicular to the base.

Aluminum and plastic were used to construct the receiving antenna elevation positioning bracket. The C-shaped bracket slid freely along the upright arm with the gap in the "C" allowing movement past the vertical brace. A chuck holding the receiving antenna was set in a hole drilled in an extension of the bracket. A simple brake held the entire assembly at any desired elevation. This bracket held the pick-up antenna in a plane perpendicular to the base of the positioner and containing the center of the base. By loosening a set screw, the chuck and receiving antenna could be oriented for any desired polarization. The chuck clamped the receiving antenna securely so that a constant separation was maintained between transmitting and receiving antennas for any receiving antenna position. At the same time, the chuck could be loosened and waveguide added or removed to change the separation between antennas.

A standard gain horn of aperture dimensions $22 \times 17 \mathrm{~mm}$ was used throughout the experiment as the receiving antenna. Gain of the test antenna was determined by comparison of the test antenna signal 
power level with that of a standard gain horn, calibration data of that horn being supplied by the manufacturer.

For measurements made at a separation of $R=420 \mathrm{~mm}$ the far-field criterion, eq (27), was met. This was confirmed for various test antennas by moving the receiving antenna into the separation distance $R=210 \mathrm{~mm}$ at which location $202 / \lambda=R$. The normalized patterns observed at $210 \mathrm{~mm}$ and $420 \mathrm{~mm}$ were identical.

The antenna positioner was able to maintain the separation of $410 \mathrm{~mm}$ within $1 \mathrm{~mm}$. This is far too much variation for accurate phase measurement but the effect on power pattern measurements was negligible.

Elevation angle of the positioner was accurate to less than $1^{\circ}$ when measuring at discrete positions. However, for continuous sweeping over a given plane, this accuracy was limited by the recording device (see below).

Azimuthal angle of the positioner was accurate to within $\pm 1^{\circ}$ for the major axes. Only the major axes $\left(0^{\circ}, 45^{\circ}, 90^{\circ}\right.$, etc.) were scaled since other azimuthal positions were not required. Addition of a complete $360^{\circ}$ azimuthal scale could be easily accomplished for any future use of the positioner.

Obviously, as with any antenna range, proper alignment of the test antenna with respect to the range was essential. Great care was taken to center the test antenna properly and to level the antenna range base and the test antenna ground plane in the same plane. Repeatability of patterns when the test antenna was rotated $180^{\circ}$ and measurement of the same peak signal level in several azimuthal planes for the standard gain horn confirmed the accuracy of the range alignment process.

Absorbing material was appropriately placed around the range and behind the transmitting and receiving antennas. This eliminated all known multipath and other range reflection problems.

The far-field spherical positioner was quite suitable for the measurements to be made. Errors due to the positioner were insignificant when compared with noise and recorder errors discussed in the next section.

Experimental Setup

After the necessary equipment, as described above, and the first antennas for testing were constructed, the setup described below and illustrated in figure 5 was assembled. This system consisted of five sub-systems: the millimeterwave source, the test antenna, the testing devices, the receiving system, and the output and recording devices.

The millimeter source was a klystron. Observed range of this klystron was 59.1 to $65.6 \mathrm{GHz}$ with maximum power output on the order of a few milliwatts. Amplitude and frequency drift were negligible; even without a phase-locking system, frequency drift amounted to less than $10 \mathrm{MHz}$ total frequency deviation over a one hour period and, in most cases, less than $3 \mathrm{MHz}$ over the course of any set of measurements. Power output as monitored was also very stable, with a maximum deviation of 0.1 dB over one hour and generally less than $0.03 \mathrm{~dB}$ over any set of measurements. Broadband isolators were used to minimize loading and resonance effects on the klystron. A tuner improved the match of the system to the klystron.

The antennas and test equipment have been previously discussed. However, the method of mounting the antenna to the waveguide is to be noted here. 
A short section of waveguide was filed so that its walls were very narrow at the end. With the antenna lying on a flat surface, the waveguide was aligned with the antenna iris and soldered at the antenna ground $\mathrm{plane.} \mathrm{Visible} \mathrm{inspection} \mathrm{of} \mathrm{the} \mathrm{inside} \mathrm{of} \mathrm{the} \mathrm{waveguide-ground} \mathrm{pl}$ ane joint confirmed that a good connection had been made with no holes in the joint nor solder present inside the waveguide. The quality of this procedure was further confirmed by soldering a section of waveguide to a piece of the antenna material from which copper had not been etched, effectively forming a short circuit. The measured VSWR of this short circuit was 18:1, less than $1 \mathrm{~dB}$ below that of the best short circuit available. The relatively high quality of the short circuit constructed in this manner gave confidence that the solder joints of the antennas did not significantly alter the measured antenna input parameters.

One exception to this procedure was in the case of the fully open waveguide feed. Here all the copper was removed from the back of the antenna. The very flat dielectric-patch sheet was taped firmly to a flat 180-mm-diameter brass flange terminating the waveguide. The dielectric material made good contact with the flange near the waveguide opening. Some bubbles did occur between the flange and the dielectric at distances greater than $1 \mathrm{~cm}$ from the waveguide opening but were observed to have a negligible effect on the measurement. Removing the antenna from the flange and replacing it, again smoothina out bubble near the antenna, yielded measurements repeating the original data.

The receiving system used was a phase-amplitude receiver. One channel of this receiver was connected to a 10-dB directional coupler located between the klystron and the test equipment. This provided a reference signal to frequency-lock the receiver and to monitor the klystron power output. The second channel of the receiver was connected to the pick-up waveguide of the slotted line during impedance measurements and to the receiving horn mounted in the spherical positioner during far-field power pattern measurements.

The local oscillator of the receiver generated a fundamental frequency signal in the 2 to $4 \mathrm{GHz}$ range. This signal was transmitted down a coaxial cable to a mixer connected to the millimeterwave circuit at the slotted line or the receiving antenna on one channel and to the 10 dB directional coupler on the other channel. The millimeterwave signal beat agains: the local oscillator's fundamental frequency, and its harmonics were generated by the mixer. The resulting signal products were transmitted back down the coaxial cable to the receiver which locked onto the appropriate intermediate frequency signal. This was then heterodyned to $1000 \mathrm{~Hz}$ and amplified, and the output of both channels was fed to a linear-logarithmic amplifier. The power output of the klystron, sampled by the reference channel, was monitored on the amplifier's digital display. By means of a frequency counter the signal product frequencies just above and just below the fundamental produced by the local oscillator were determined. From this information the klystron operating frequency was calculated with an error of, at most, $1 \mathrm{kHz}$.

Output of the test channel of the linear-logarithmic amplifier was connected to a voltmeter for impedance measurements and to a chart recorder for pattern measurements. Although an $x-y$ recorder and an elevation angle sensor on the spherical positioner would have provided more accuracy for swept position measurements, careful sweeping of the receiving antenna assembly and repetition of the measurements provided accuracy of better than $\pm 5^{\circ}$. This accuracy was suitable for the broad beamwidths to be measured in the experiment and was improved by comparing swept position measurement with discrete position measurements.

Signal power level was calibrated by comparison of the test antenna signal with the peak signal of the standard gain horn. Output power of the horn was controlled by a precision variable 
attenuator. Settings of the attenuator were noted along with the receiving power level for both antennas. The gain of the test antenna was then determined from this information and the manufacturer's calibration data for the horn, having an accuracy of $\pm 0.25 \mathrm{~dB}$. Noise on the received signal, however, limited the accuracy of gain measurements to $\pm 0.5 \mathrm{~dB}$.

\section{Impedance Measurement Procedure}

Impedance measurements using the slotted line were made by the variable attenuator method. As the probe was moved down the slot, a constant signal level was maintained at the probe output by varying the setting of the precision attenuator. Attenuation values were noted at a sequence of peaks and nulls. An average peak value was determined from the observed attenuator settings by first converting the value for each peak to its linear magnitude and then averaging all such peak readings together. The average null value was determined similarly. Finally, the square root of the ratio of the average peak and null readings was taken to obtain the VSWR. These peak and null readings were usually within $\pm 0.5 \mathrm{~dB}$ of the average reading although in a few cases readings were observed to differ by up to $\pm 0.75 \mathrm{~dB}$.

Due to the high sensitivity of the receiver the probe needed to be inserted only $0.05 \mathrm{~mm}$ into the slotted section and was maintained at that depth for all measurements. This amount of probe penetration excited the pick-up waveguide sufficiently for virtually noise-free measurements yet without adding a significant susceptive or conductive load to the slotted section.

Null positions were observed and recorded to obtain phase information. By measuring to the accuracy of the slotted line $( \pm 0.005 \mathrm{~mm})$ the distance from a reference $\mathrm{plane}$ on the slotted line to the antenna ground $\mathrm{plane}$, use of a reference short was unnecessary. These measurements were made with a high-precision optical scale. Since, as previously mentioned, calculated and measured guide wavelength were virtually identical, the phase shift of the standing-wave pattern under observation could be determined from knowledge of these measured dimensions, along with the position of the probe at the null and the frequency. The normalized input impedance of the antenna under test was then calculated by the formulas [9]

$$
\begin{gathered}
R_{i n}=\frac{r}{r^{2} \cos ^{2}(\beta \Delta s)+\sin ^{2}(\beta \Delta s)}, \\
x_{\text {in }}=\frac{\left(1-r^{2}\right) \cot (\beta \Delta s)}{r^{2} \cot ^{2}(\beta \Delta s)+1},
\end{gathered}
$$

and

$$
r=\text { VSWR, }
$$

where

$$
\begin{aligned}
\Delta s= & \text { null shift with respect to a short } \\
& \text { circuit, shift toward load implies } \\
& +\Delta s .
\end{aligned}
$$

\section{Experimental Results}

Several antennas were fabricated according to the methods outlined in section 3 . The iris was centered with respect to the patch in each case. Patch and iris dimensions and the size of the iris relative to the patch and relative to the waveguide cross-sectional area are noted in table 2 . The 
resonant frequency predicted by the transmission-line model [8] and by the modal-expansion model [9] and the percentage differences between the observed and predicted values are presented as well. Finally, the normalized input impedance, $Z_{\text {res }}$, of the antenna at resonance is noted.

The resonant frequency has been defined to be the frequency at which the final term of eq (3) is purely real. This corresponds to the solution of eq (9). Experimentally, resonance was seen to occur at a minimum in the measured VSWR, thus at a minimum in the magnitude of the reflection coefficient, $|\Gamma|$.

Table 2. Antenna parameters.

$\begin{array}{lllllllll}\text { Antenna } & \text { No. } 1 & \text { No. } 2 & \text { No. } 3 & \text { No. } 4 & \text { No. } 5 & \text { No. } 6 & \text { No. } 7 & \text { No. } 8 \\ \begin{array}{l}\text { Material } \\ \left(\varepsilon_{r}\right)\end{array} & 2.20 & 2.20 & 2.20 & 2.20 & 2.20 & 2.20 & 10.5 & 10.5 \\ \begin{array}{l}\text { Patch dimensions } \\ \quad \text { (mm) }\end{array} & 1.50 & 1.49 & 1.49 & 1.49 & 1.49 & 1.49 & 1.49 & 1.44 \\ \quad \ell(\mathrm{mm}) & 1.25 & 1.23 & 1.23 & 1.23 & 1.23 & 1.23 & 1.23 & 1.12\end{array}$

Iris dimensions

$D(m \mathrm{~m})$

$0.8862 \quad 0.745$

0.745

0.725

0.745

1.450

1.588

d $(\mathrm{mm})$

0.862

0.451

0.372

0.392

1.156

1.333

Observed resonant

frequency

( $\mathrm{GHz})$

$63.2 \quad 63.1$

62.7

62.7

63.6

63.4

62.0

60.7

Predicted resonant

frequency

(trans. line)

$(\mathrm{GHz})$

67.

Error (trans. line)

(\%)

Predicted resonant

frequency

(modal expan-

sion)

$62.4 \quad 62.8 \quad 62.8$

$-6.2 \quad-7.1$

$-7.7$

$-7.7$

$-6.3$

$-6.6$

$-8.7$

Error (modal

expansion

$(\%)$

0.5

$-0.2$

$-0.2$

1.3

1.0

$-1.3$

Iris Area

(\%)

39.5

15.9

18.7

14.7

15.9

91.2

115.0

Iris Area

$(\%)$

10.4

4.1

4.7

3.8

4.1

23.5

29.6

100.0

$\frac{z_{\text {in }}}{z_{10}}$ (at resonance)

$\begin{array}{llllllll}0.23+ & 0.30+ & 0.20+ & 0.15+ & 0.50+ & 0.20+ & 0.17+ & 0.33+ \\ j 0.31 & j 0.40 & j 0.42 & j 0.32 & j 1.37 & j 0.22 & j 0.25 & j 0.00\end{array}$


The frequency of minimum $\left|Y_{i n} / Y_{10}\right|$, and consequently that of minimum $|\Gamma|$, could be determined by differentiating eq (3) with respect to frequency and setting that expression to zero. The dependence of eq (3) on $\omega$ is quite complicated and an analytical solution difficult to find. Calculation of $Y_{i n} / Y_{10}$ for several frequencies, and from that $\Gamma$, provides an easier means of showing that the resonance does indeed correspond to a minimum in VSWR.

As an example, calculation is made of $Y_{i n} / Y_{10}$ for antenna No. 1. Dimensions of this antenna are noted in table 2. The magnetic mode vectors, $\bar{h}_{\mathrm{mn}}$, of the antenna are defined to be those of eq (7). The electric field tangential aperture distribution is approximated by

$$
\bar{E}_{t}^{a}=\bar{a}_{y} j E_{10} \sin \frac{\pi}{D}\left(x-\frac{(h-D)}{2}\right)
$$

with respect to the coordinate system of figure 1 . Calculating the $b_{m n}$ up to $b_{33}$ and finding $\omega_{m n}$ from eq (8) for $m n \neq 10$ results in the $B_{c}$ noted in table 3 . From eq (1) $B_{f}$ is found for the given iris dimensions and $B_{g}$, as also noted in table 3 , is assumed to be one-half that value. From eq (9), as described below, $\omega_{10}$ is found. From this and $b_{10}$ the final term of eq (3), labeled as $f\left(b_{10}\right)$ in table 3 , is calculated. The dominant mode characteristic wave admittance of the waveguide, $Y_{10}$, is calculated from $Y_{10}=\left(1-\left(f_{c} / f\right)^{2}\right) \frac{1}{2} / Z_{0}$ where $Z_{0}=377 \Omega$ and $f_{c}$ is the waveguide cutoff frequency. Finally, $V_{10}$ is $E_{10}(a b / 2)^{1 / 2}$ where $a b$ is the waveguide cross-sectional area, $3.78 \times 1.89 \mathrm{~mm}$. From this, $Y_{i n} / Y_{10}$ is calculated as well as the corresponding reflection coefficient,

$$
\Gamma=\frac{1-Y_{i n} / Y_{10}}{1+Y_{i n} / Y_{10}} .
$$

These are noted in table 3. The calculated values indicate that $|\Gamma|$ does indeed have a minimum at $62.4 \mathrm{GHz}$, the resonant frequency predicted by the solution to eq (9).

Table 3

\begin{tabular}{|c|c|c|c|c|c|c|c|c|}
\hline $\begin{array}{l}\text { Frequency } \\
\qquad \underline{\mathrm{GHz}}\end{array}$ & $\mathrm{B}_{\mathrm{g}}$ & $\begin{array}{c}B_{c} / v^{2} \\
(\mathrm{~s} / \mathrm{m}) \times 10^{-9} \\
\end{array}$ & $\begin{array}{c}f\left(b_{10}\right) \\
(\mathrm{s} / \mathrm{m}) \times 10^{-8} \\
\end{array}$ & $\begin{array}{c}\frac{1}{Y_{10}} \\
\underline{(\Omega)} \\
\end{array}$ & $\frac{Y_{\text {in }}}{Y_{10}}$ & $\Gamma$ & $\frac{Y_{\text {in }}}{Y_{10}}$ & $\Gamma^{\prime}$ \\
\hline 60.0 & -20.3 & -2.18 & $2.63220^{\circ}$ & 501 & $21.3-86^{\circ}$ & $0.994175^{\circ}$ & $3.37-65^{\circ}$ & $0.793149^{\circ}$ \\
\hline 62.4 & -20 & -2.15 & $3 . 3 1 \longdiv { 1 8 0 ^ { \circ } }$ & 487 & $20.5-84^{\circ}$ & $0.989174^{\circ}$ & $3.13-44^{\circ}$ & $0.640154^{\circ}$ \\
\hline 63.2 & -20.1 & -2.15 & $3.12 \frac{163^{\circ}}{}$ & 483 & $20.9-85^{\circ}$ & $0.991175^{\circ}$ & $3.43 \frac{1}{-54^{\circ}}$ & $0.721153^{\circ}$ \\
\hline 65.0 & -19.8 & -2.13 & $2.26 \overline{135^{\circ}}$ & 474 & $21.0-87^{\circ}$ & $0.996175^{\circ}$ & $3.34 \overline{-71^{\circ}}$ & $0.838148^{\circ}$ \\
\hline
\end{tabular}

Calculated reflection coefficient and related parameters for antenna No. 1

To further illustrate the point, $\left(Y_{i n} / Y_{10}\right)^{\prime}$ and $\Gamma^{\prime}$ are calculated using a value $B^{\prime} g=B_{g} / 10$. Maintaining the same values of the other parameters used above results in a calculated input 
admittance more in line with that actually measured. The minimum in $\left|\Gamma^{\prime}\right|$ occurring at $62.4 \mathrm{GHz}$ and the phase variation are more pronounced in this case since $B^{\prime} g$ does not have as much effect on the calculated $\left(Y_{i n} / Y_{10}\right)^{\prime}$ as $B_{g}$ does on $Y_{i n} / Y_{10}$.

Inspection of eq (3) reveals that there is more than one minimum of $\left|Y_{i n} / Y_{10}\right|$. Indeed, differentiating eq (3) with respect to frequency, after all of the frequency dependent effects have been included, results in an equation of fifth order in $\omega$. Thus, there are at least two, if not three, minima of $\left|Y_{i n} / Y_{10}\right|$. The locations of these minima depend on the geometry of the antenna and of the waveguide feed.

Unless the phase of $Y_{i n} / Y_{10}$ has the appropriate magnitude and is rapidly varying, $|\Gamma|$ will have minima at the minima of $\left|Y_{i n} / Y_{10}\right|$. It follows, then, that for the antennas studied it is reasonable to assume that the resonant frequency occurs at a frequency of minimum VSWR.

This statement is not true in general for microstrip patch antennas. This is seen in the case where $Y_{10}$ has approximately the same magnitude as the resonant input admittance of the antenna and the susceptance due to the feed, $B_{g}$ and $B_{C}$, is non-zero. Minimum VSWR will occur at some frequency where $\mathrm{B}_{\mathrm{g}}$ and $\mathrm{B}_{\mathrm{C}}$ tend to cancel the imaginary portion of the last term of eq (3), not where that term is purely real.

The calculated resonant frequency was determined from the various antenna parameters, listed in table 1 and table 2, and using the transmission line model [2] and the modal expansion model [3]. This second predicted frequency is also the resonant frequency predicted by the iris feed model.

For antenna No. 1 , as an example $\left(\varepsilon_{r}=2.2, h=1.50 \mathrm{~mm}, l=1.25 \mathrm{~mm}, t=0.127 \mathrm{~mm}\right)$, the calculations proceeded as follows. For the transmission line model, $\varepsilon_{r}$ and $h$ were needed only to obtain a predicted resonant frequency of $67.4 \mathrm{GHz}$. For the modal expansion model, $Y_{W}$ was estimated to be $0.0024++j 0.00456$. This was obtained by inserting the appropriate antenna parameters into eqs (13), (14), (16), and (17). A value of $\lambda_{0}$ was assumed equal to 1.04 times the wavelength corresponding to the resonant frequency. Using $\Delta_{0}=0$ as a seed, eq (9) was solved by taking four iterations of eq (12). The resulting $k_{10}$ found from eq (11) was $k_{10}=1939+j 85.0 \mathrm{~m}^{-1}$ corresponding to $f_{r}=c k_{10} / 2 p \sqrt{ } \varepsilon_{r}=62.4+j 2.7 \mathrm{GHz}$. Thus the predicted resonant operating frequency of antenna No. 1 by this model is $62.4 \mathrm{GHz}$.

In figure 6 and figure 7, the VSWR and input impedance of antenna No. 1 are plotted as a function of frequency. The input impedance, as displayed, is referenced to the ground plane of the antenna and includes feed effects. All input impedance plots presented in this chapter are similarly referenced to the antenna ground plane.

Inspection of figure 6 indicates that the resonant frequency of the antenna occurs at $63.2 \mathrm{GHz}$, the frequency of minimum VSWR of the antenna. As plotted in figure 7 , the normalized input impedance of the antenna at resonance is $Z_{\text {res }}=0.21+j 0.31$. The predicted input impedance eq (3) is $\left(Y_{i n} / Y_{10}\right)^{-1}=0.0046+j 0.0476$. It is obvious that there is a 1 arge discrepancy between the predicted and the observed input impedances. This is due to error in the approximation of $B_{g}$. The calculated value of $B_{g}$ is much larger than that indicated by the measurements. If $B^{\prime} g$ and $\left(Y_{i n} / Y_{10}\right)^{\prime}$ are used instead, as noted in table 3 , a more reasonable predicted input impedance of $0.23+j 0.22$ is obtained. Evidently the model for the iris feed gives a good qualitative analysis of the problem but fails to completely account for the susceptance introduced by the iris. A similar analysis holds for the other antennas studied. 
In figure 8 the $\mathrm{H}-\mathrm{pl}$ ane $\left(\phi=0^{\circ}\right)$ and E-plane $\left(\phi=90^{\circ}\right)$ far-field power patterns of antenna No. 1 are presented for operation at $63.2 \mathrm{GHz}$. Using the standard gain horn as a reference the gain of antenna No. 1 was measured to be $4.0 \mathrm{~dB}$ relative to an isotropic source (dBi), that is, $4.0 \mathrm{~dB}$ greater power received by a test antenna at the peak of the power pattern than the power received as transmitted from an isotropic radiator with equal input power. Note that the peak power level indicated by figure 8 is approximately $1.3 \mathrm{dBi}$. The figure $4.0 \mathrm{dBi}$ takes into account the loss due to the 4.8:1 VSWR at this frequency. Throughout this report the power patterns are drawn and scaled as they were measured. Comments in the text correlate the measured signal level with the mismatch to give the antenna gain.

The patterns are fairly smooth and broad, as expected for the microstrip patch antenna. Small undulations are assumed to be due to the effects of a finite ground $p l a n e\left(5 \times 7 \lambda_{0}\right.$ at resonance for this antenna and similar for the other antennas). The $H-p l a n e ~ 10 \mathrm{~dB}$ beamwidth is observed to be $135^{\circ}$ while the E-plane power level is down $10 \mathrm{~dB}$ in the $\theta=90^{\circ}$ plane. This compares to a predicted [10] $10 \mathrm{~dB} \mathrm{H}$-plane beamwidth of $166^{\circ}$. A virtually identical H-plane beamwidth was predicted [10] for each of the antennas No. 2 through No. 7 , yet, as will be seen, with similarly narrower observed beamwidths.

In figure 9 the $\mathrm{H}$-plane pattern for antenna No. 1 is presented for operation at 65.4 and 59.2 GHz. The patterns are again quite broad and smooth, as at resonance, and the gain is observed to be $4.5 \mathrm{dBi}$ and $4.0 \mathrm{dBi}$ respectively. One would expect a slightly higher gain for the higher frequency since the radiating aperture is electrically larger.

For this and all antennas tested the polarization of the far-fields was linear and in the $y$ direction (fig. 1). The cross-polarized signal level was, in general, weak enough to be entirely obscured by noise.

Antennas No. 2 through No. 5 were constructed with identical patch and nearly identical iris dimensions as noted in table 2. Antennas No. 2 and No. 3 were both soldered to the waveguide section so that the iris was centered with respect to the waveguide opening, as were all of the antennas except No. 4 and No. 5. Antennas No. 4 and No. 5 were connected so that the iris was off-centered along the long axis and short axis, respectively, of the waveguide but with the iris, as always, centered with respect to the patch. This is illustrated in figure 10.

In figure 11 through figure 14 the VSWR and Smith chart input impedance loci for antennas No. 2 and No. 3 are presented. Ideally, identical results should have been observed for the two antennas. It is seen from the VSWR curves that the resonance of antenna No. 2 occurs at $63.1 \mathrm{GHz}$ and that for antenna No. 3 at $62.7 \mathrm{GHz}$, corresponding to errors of 0.5 percent and -0.2 percent respectively in comparison with the predicted resonant frequency. This small discrepancy is attributable to small differences in the patch size and secondarily, to minor variations in $\varepsilon_{r}$. The other minima of figure 11 and figure 12--and indeed for the VSWR vs. frequency curves of antennas No. 4 through No. 7--are due to the complicated interaction between the patch, the iris, and the waveguide, as previously discussed. Looking ahead, one notes that there is a minimum in the VSWR vs. frequency curves for each of the antennas No. 2 through No. 7 near the predicted resonance frequency, $62.8 \mathrm{GHz}$. Other minima occur in each of these curves but no consistency is noted between antennas. Thus it is assumed that the resonance of the antenna occurs at that minimum near $62.8 \mathrm{GHz}$ and that the other minima are due to the patch-iris-waveguide interaction. 
If one ignores the local maxima in VSWR at $62 \mathrm{GHz}$ for antenna No. 3, and instead assumes that the curve follows the dotted line drawn in that plot, similarity is readily noted between the VSWR curves of antennas No. 2 and No. 3, with the curve of antenna No. 3 shifted downward in frequency. The input reactance, as seen on the Smith chart plots, is also nearly identical over the range of observation.

Discrepancies can be attributed to small variations in patch size, dielectric constant, and patch-iris and iris-waveguide alignment. This would indicate, as previously suggested, that human and measurement errors are greater for VSWR measurements than for phase measurements.

The $\mathrm{H}$ - and E-plane far-field power patterns of antenna No. 3 are shown in figure 15 for operation at $62.7 \mathrm{GHz}$. The signal level was low at this frequency of operation. Consequently, the peak-to-peak noise level was $2 \mathrm{~dB}$ at maximum received signal. This was nearly triple the noise level for all other measurements. Even with this noise level the pattern was discernible and is seen to be broad in both planes and similar to the patterns of antenna No. 1. The small hump in the pattern in both planes is due to the finite ground $\mathrm{plane}$ and, possibly, due to the antenna not being perfectly flat as mounted. Gain of antenna No. 3 at resonance is seen to be $1.5 \mathrm{dBi}$. The patterns of antenna No. 2 were similar to these, at $63.1 \mathrm{GHz}$, but even noisier due to low klystron output power.

Although not identical, the measured parameters of these two antennas are relatively close to one another. It is felt, then, that the construction of the antennas, and particularly the antennawaveguide soldering procedure, was done in a repeatable fashion. The soldering of the antenna to the waveguide did not introduce any appreciable errors to the system as one would have expected had solder leaked into the waveguide or had holes been left between the two pieces. Improvements would need to be made at all steps of the fabrication process to improve repeatability between antennas significantly.

The VSWR vs. frequency curves and the Smith chart input impedance loci of antennas No. 4 and No. 5 are presented in figure 16 through figure 19. Resonance is seen to occur at $62.7 \mathrm{GHz}$ and $63.6 \mathrm{GHz}$, respectively.

The normalized resonant reactance of antenna No. 4 is j0.32 as compared to $j 0.40$ and j0.42 for antennas No. 2 and No. 3. This indicates that the feed of this antenna is more capacitive. Moving the iris in the $x$ direction away from the center of the waveguide results in less disruption of the magnetic fields due to the iris. The result is a net reduction in stored magnetic energy causing the antenna to be more capacitive.

Moving the iris location in the $x$ direction also reduces the transverse magnetic dipole in the aperture, decreasing the coupling into the antenna. This is seen in that the resonant VSWR is higher for this antenna than for the centered iris case.

Antenna No. 5 is seen to be much more inductive than antenna No. 3 with a resonant normalized reactance of j1.37. Moving the small iris in the $y$ direction, but not the $x$ direction, causes no change in the magnetic field strength over the small iris in comparison to the centered case eq (19). Evidently there is a significant change in the total electric field near the aperture with less stored electric energy for antenna No. 5 than for antenna No. 2 and No. 3.

The mismatch of this antenna to the waveguide was very high across the whole frequency range observed. Coupling of energy into the antenna was so inefficient that the radiated signal was too small for significant far-field power pattern measurement. 
In figure 20 the far-field $H$ - and E-plane patterns of antenna No. 4 are presented for operation at $62.7 \mathrm{GHz}$. The patterns were similar at $63.9 \mathrm{GHz}$ and at $60.5 \mathrm{GHz}$ where other minima occurred in the VSWR curve. Antenna gain at $62.7 \mathrm{GHz}$ is seen to be $1.5 \mathrm{dBi}$. The $\mathrm{H}-\mathrm{pl}$ ane $10 \mathrm{~dB}$ beamwidth is observed to be $130^{\circ}$ while the E-plane power level is down $5 \mathrm{~dB}$ in the $\theta=90^{\circ}$ plane. Gain at $63.9 \mathrm{GHz}$ was 2.0 $\mathrm{dBi}$ while at $60.5 \mathrm{GHz}$ it was $-4 \mathrm{dBi}$, significantly lower.

The VSWR vs. frequency curve of figure 21 and the related input impedance locus plotted in figure 22 indicate that the resonance of antenna No. 6 occurs at $63.4 \mathrm{GHz}, 1.0 \%$ above the predicted resonant frequency of $62.8 \mathrm{GHz}$. At this frequency, $\mathrm{H}$ - and $\mathrm{E}-\mathrm{pl}$ ane far-field power patterns were observed as presented in figure 23. The antenna gain as measured at the peaks of the power pattern is $2.5 \mathrm{dBi}$. The $H$-plane $10 \mathrm{~dB}$ beamwidth is $140^{\circ}$ while the $E-p l$ ane power level is down $11 \mathrm{~dB}$ in the $\theta=90^{\circ}$ plane. The undulations in the pattern are due not only to the finite ground $p l a n e$ but also indicate some interaction between the radiation of the patch and a secondary radiation from the iris feed. This is not unexpected since the size of the iris of this antenna is $91.2 \%$ of the size of the patch.

In figure 24 and figure 25 the VSWR and input impedance locus of antenna No. 7 are plotted. Resonance occurs at $62.0 \mathrm{GHz}$, the center of the broad minimum in VSWR. At this frequency, $1.3 \%$ below the predicted resonant frequency, $62.8 \mathrm{GHz}$, the gain was measured to be $3.0 \mathrm{dBi}$. The $\mathrm{H}-\mathrm{pl}$ ane $10 \mathrm{~dB}$ beamwidth is $120^{\circ}$ while the E-plane power level is down $9 \mathrm{~dB}$ at $\theta=90^{\circ}$, as seen from figure 26 .

The far-field power pattern for this antenna at resonance shows a dip at $\theta=0^{\circ}$ as did antenna No. 6. Again this is to be attributed to interference between radiation from the patch and radiation from the iris. In this case the iris is even bigger, 115 percent of the size of the patch. In figure 27 the far-field power pattern of antenna No. 7 is illustrated for operation at $65.1 \mathrm{GHz}$. Off resonance there is seen to be even greater disruption of the antenna far-field pattern, particularly in the region $\theta=-30^{\circ}$ to $\theta=0^{\circ}$ in the $\mathrm{H}$-plane. This interference effect is even more pronounced for antenna No. 8 , the antenna fed by the fully-open waveguide.

Antenna No. 8 was constructed from a material with substrate dielectric constant $\varepsilon_{r}=10.5$. Patch size for the antenna was $1.40 \times 1.12 \mathrm{~mm}$. According to the transmission line model [8] the antenna should have been resonant at $33 \mathrm{GHz}$. Instead, the antenna was observed to resonate at 60.7 $\mathrm{GHz}$ as indicated from the minimum in the VSWR vs. frequency curve of figure 28 and the input impedance locus of figure 29. Investigation of smaller patches (roughly $0.7 \times 0.5 \mathrm{~mm}$ ) revealed that no resonance occurred for those patches in the 60 to $65 \mathrm{GHz}$ range. Consequently, $60.7 \mathrm{GHz}$ is taken to be the dominant mode resonant frequency of this antenna. Removal of all of the copper from under the patch radically changes the nature of the antenna. The wall admittances can no longer be accurately predicted by eq (13) and eq (14) precluding the use of eq (9) to predict the resonant frequency. Indeed, the antenna is no longer truly a microstrip device but only similar to microstrip.

The far-field $\mathrm{H}$ - and E-plane power patterns of antenna No. 8 are presented in figure 30 . The smooth, single-lobed pattern again indicates that the antenna is resonant in the dominant mode rather than a higher order mode resonance. Gain of the antenna is $0.0 \mathrm{dBi}$. Figure 31 illustrates a much different $\mathrm{H}-\mathrm{pl}$ ane pattern for the antenna operated off resonance. The deep dip in the center of the pattern indicates that at this frequency, $65.3 \mathrm{GHz}$, the patch is acting more as a reflector and scatterer of radiation from the open waveguide rather than constructively interfering as at the resonant frequency.

Finally, in figure 32 the $\mathrm{H}-\mathrm{pl}$ ane pattern is shown for several frequencies with the patch offcenter $0.8 \mathrm{~mm}$ in the +x-direction (figure 1) with resect to the center of the waveguide. This figure 
clearly shows the scattering nature of the patch. The change in the patterns with frequency is due to the varying degree of excitation of the dominant mode of the patch and to the changing electrical lengths of the antenna geometry.

\section{Conclusion}

A model was proposed to describe the iris-fed patch antenna based on aperture coupling to cavities. This model provided a good qualitative understanding of the iris-fed antenna although the calculated input impedance did not correlate highly with the measured data.

Experimental analysis was made for a variety of iris-fed patch antennas. Antennas with iris feeds of sizes ranging from 15 percent to 115 percent of the patch size typically exhibited a minmum VSWR in the waveguide of 5:1. The fully-open waveguide feed had a significantly lower reflection coefficient with a VSWR in the waveguide of 2.9:1 at resonance.

It was experimentally demonstrated that the resonant frequency of the antenna could be predicted with high accuracy by the formula related to the modal expansion model even when the iris was 15 percent larger than the patch. This was not the case for the fully-open waveguide feed.

Far-field power patterns were observed for all antennas. Maximum gain for any antenna was 4.5 $\mathrm{dBi}$ with $2 \mathrm{dBi}$ typical. Interference between the radiation from the patch and secondary radiation from the iris feed was noted for antennas with an iris of nearly the same, or greater, size as the patch. For the fully-open waveguide feed this interference was severe except at the resonant frequency with the patch centered over the waveguide. For the smaller irises, and even for the iris slightly greater in size than the patch, the far-field patterns were quite broad with $\mathrm{H}$-plane $10 \mathrm{~dB}$ beamwidths on the order of $130^{\circ}$ and the power level down $10 \mathrm{~dB}$ in the $\theta=90^{\circ} \mathrm{plane}$.

It has been seen, then, that the iris feed of the microstrip patch antenna is worthy of consideration in the design of future antennas. In particular this is true for millimeterwave microstrip patch antennas where microstrip line and coaxial feed are impractical or unavailable.

One consideration for future study is a better understanding of the ris. Interaction between the iris, the patch, and the waveguide was seen to be rather complicated. With a better understanding of the iris behavior the iris could be designed for optimal matching of the antenna to the waveguide.

Understanding of the iris behavior requires an understanding of the relationship of the position of the iris with respect to the waveguide and with respect to the patch. The present study shows that the best coupling occurs when the iris is centered with respect to the waveguide. The iris was always centered under the patch for the antennas which were investigated. Future study should consider the coupling due to the iris when it is not centered under the patch. Determination should be made of the optimum position of the iris with respect to the patch to correlate best the fringing fields in the iris with the dominant mode fields under the patch.

This study has also been limited to coupling from the transverse plane of the waveguide feed. Consideration should also be made of feeding the antenna from a longitudinal waveguide wall. It is expected that more power could be coupled into the antenna by this feed structure since, with proper positioning, there would be both a tangential magnetic field over the aperture and a normal electric field. The transverse plane coupling gives rise to only tangential magnetic field over the aperture with no normal electric field to couple into the z-directed electric fields under the patch. Initial study of this feed structure, as reported in appendix $B$, indicates that the longitudinal feed provides 
at least as good coupling as that of the transverse feed. Refinements in the measurements could well show this to be a superior feed structure with respect to the coupling of power into the antenna.

The longitudinal feed should be studied to determine the location of the patch and iris with respect to the waveguide for optimal coupling into the antenna due to both the electric and magnetic dipoles. A sliding short circuit terminating the waveguide beyond the antenna could be used to vary the positions of the peaks and nulls in the waveguide standing wave pattern to increase coupling into the antenna fed in this way. Further, power could be coupled into several patches simultaneously from one waveguide.

Finally, application of the iris feed structure to arrays of microstrip patch antennas should be considered. Feeding of several patches should be considered. Feeding of several patches from a longitudinal wall of the waveguide is one possibility. Feeding of one patch from the waveguide and coupling from that patch into other patches could also be considered. Incorporation of electronically controllable phase shifters into the feed structure should also be investigated as a means of steering the antenna radiation.

\section{References}

[1] Lewin, L.; Chang, D. C.; Kuester, E. F. Electromagnetic waves and curved structures. Hitchin, Herts: Peter Peregrinus; 1977.

[2] Carver, K. R.; Coffey, E. L. Theoretical investigation of the microstrip antenna. Physic. and Sci. Lab., New Mexico State Univ., Las Cruces, Tech. Rep. PT-00929; 1979 January 23.

[3] Lo, Y. T.; Solomon, D.; Richards, W. F. Theory and experiment on microstrip antennas. IEEE Trans. A\&P, AP-27(2): 137-145; 1979 March.

[4] Harrington, R. F. Time harmonic electromagnetic fields. New York: McGraw-Hi11; 1961.

[5] Hammerstad, E. 0. Equations of microstrip circuit design. Proceedings of the 5th European Micro. Conf., 1975 September, Hamburg; pp. 268-272.

[6] Schneider, M. V. Microstrip dispersion. Proc. IEEE, 60(1): 144-146; 1972 January.

[7] Collin, R. E. Field theory of guided waves. New York: McGraw-Hill; 1960.

[8] Silver, S. (ed.) Microwave antenna theory and design. New York: Dover; 1960.

[9] Jasik, H. (ed.) Antenna engineering handbook. New York: McGraw-Hi11; 1961.

[10] Derneryd, A. G. Linearly polarized microstrip antennas. IEEE Trans. A\&P, AP-24(6): pp.846$851 ; 1976$ November. 


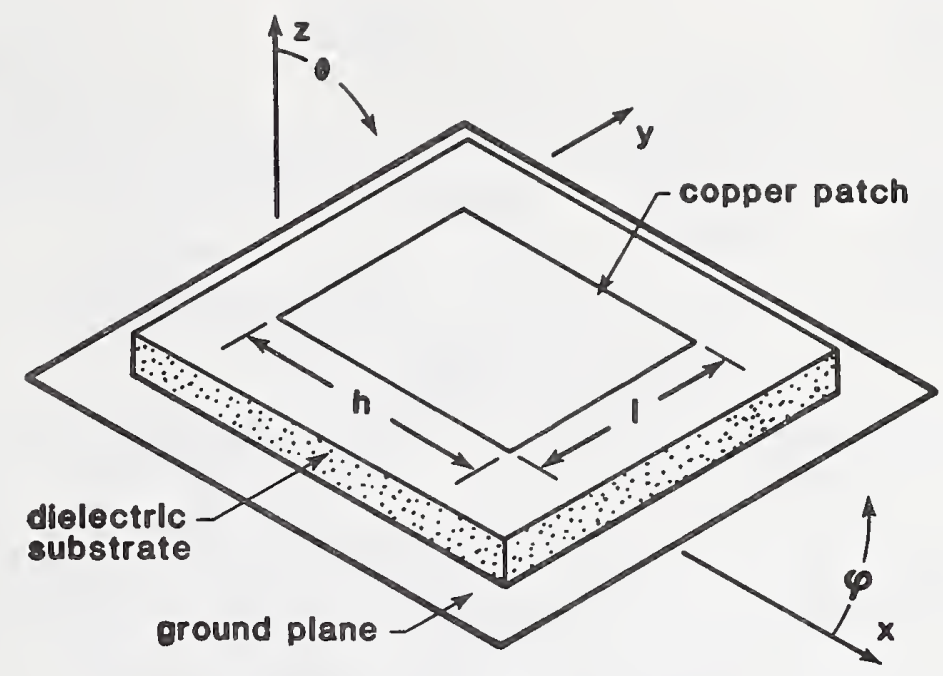

(a)

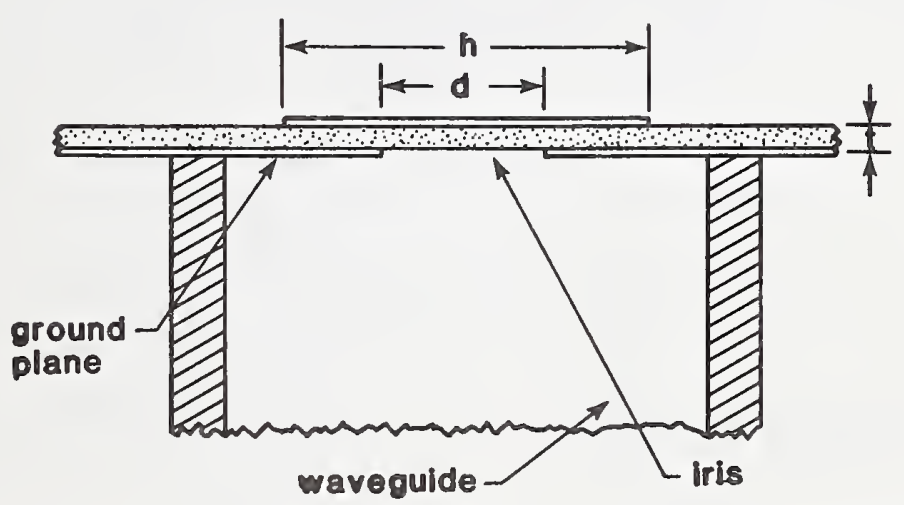

(b)

Figure 1. (a) Rectangular microstrip patch antenna.

(b) Cut-away view.

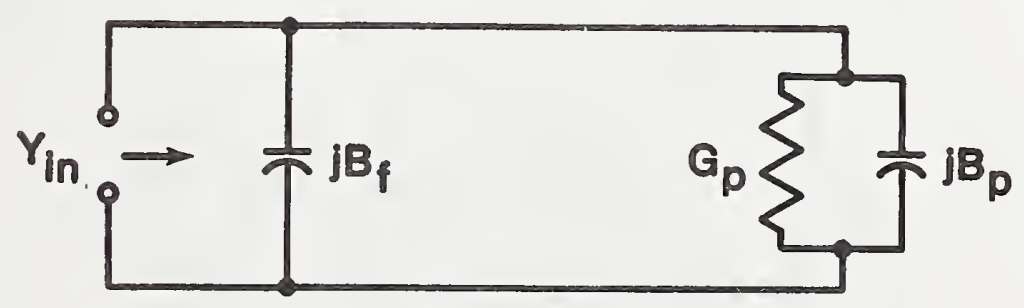

Figure 2. Simple input admittance model for the iris-fed patch antenna. 


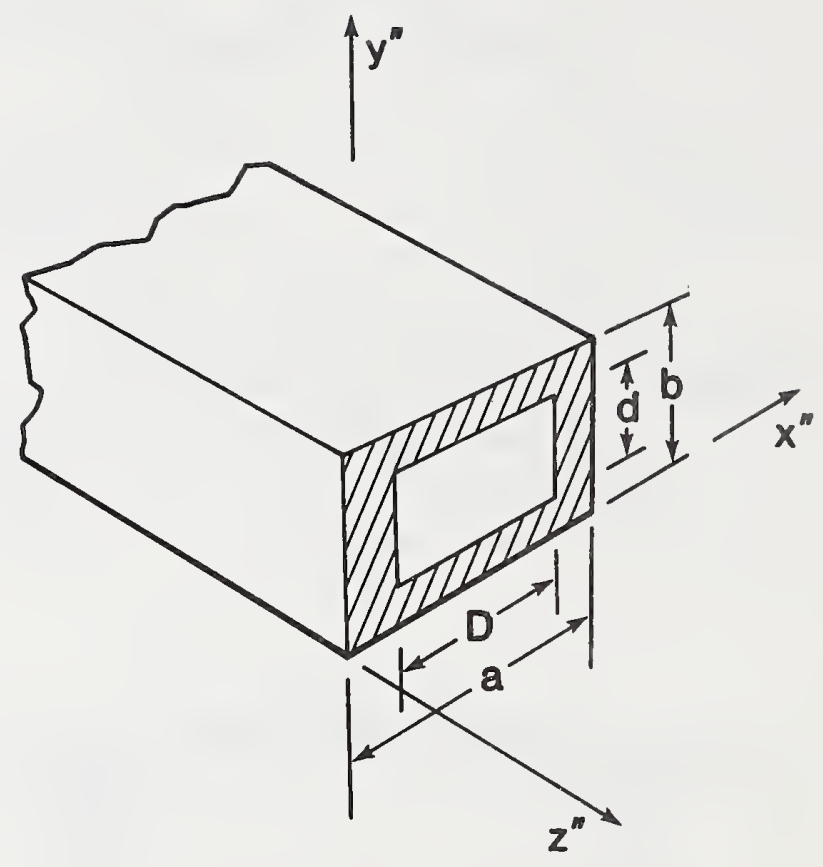

Figure 3. Centered rectangular iris terminating a rectangular waveguide.

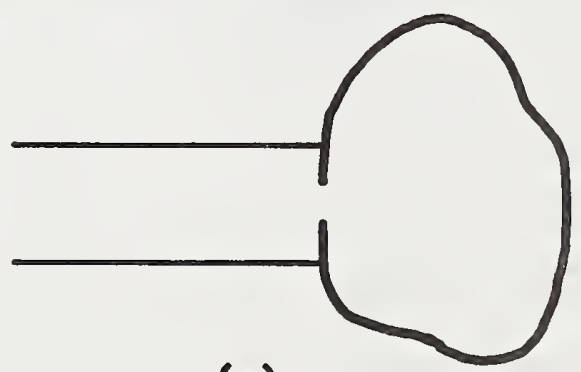

(a)

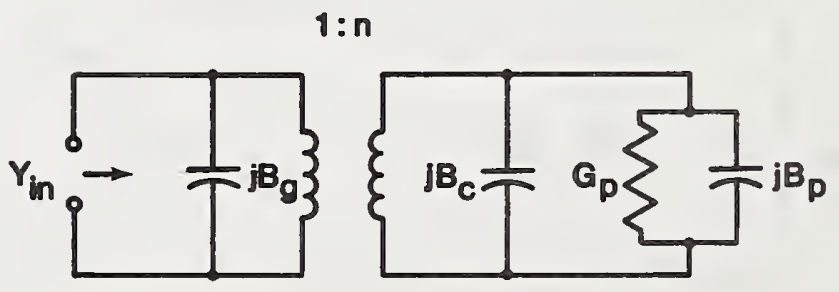

(b)

Figure 4. (a) Aperture coupling between a rectangular waveguide and a cavity. (b) Network model of the structure. 


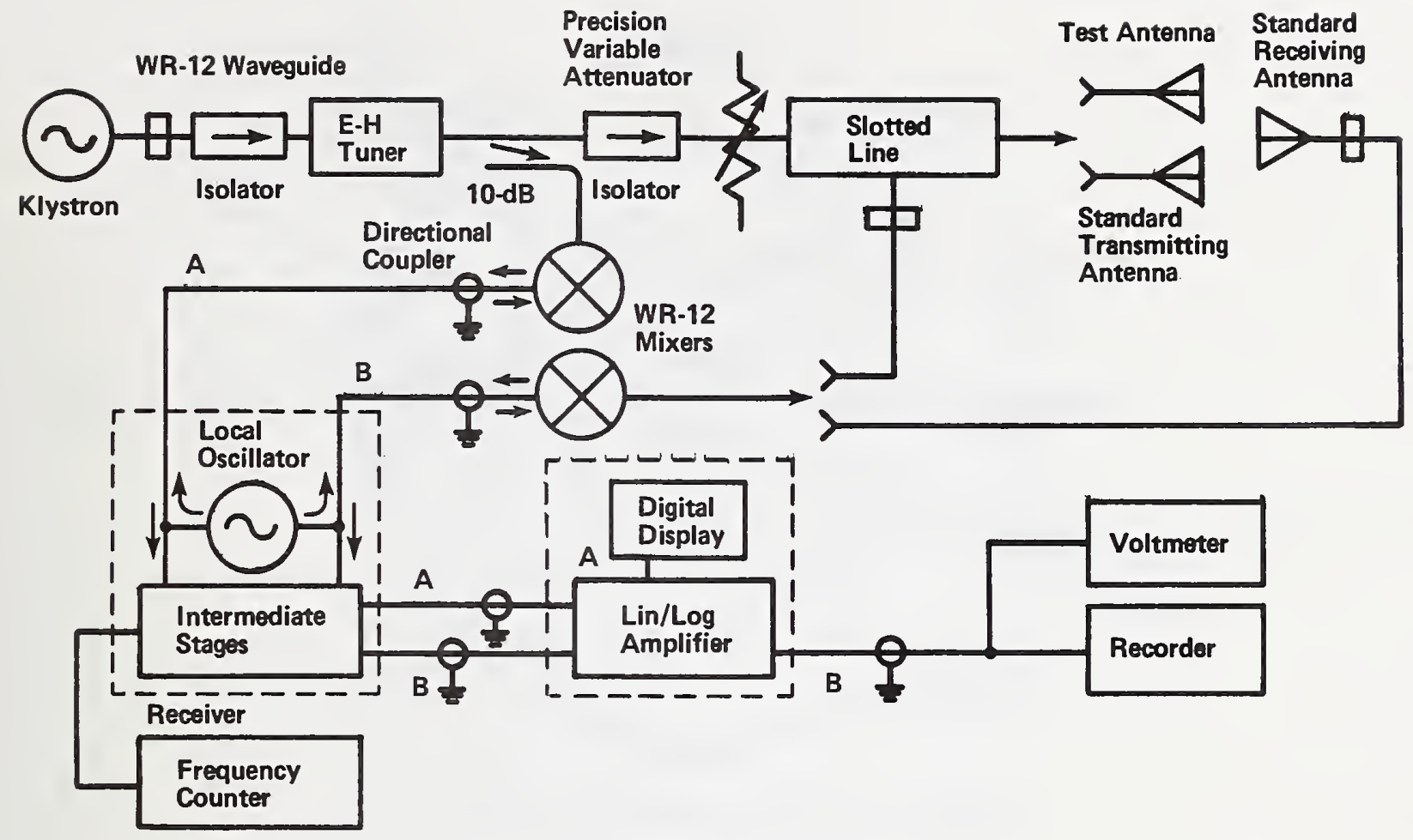

Figure 5. Block diagram of the measurement system.

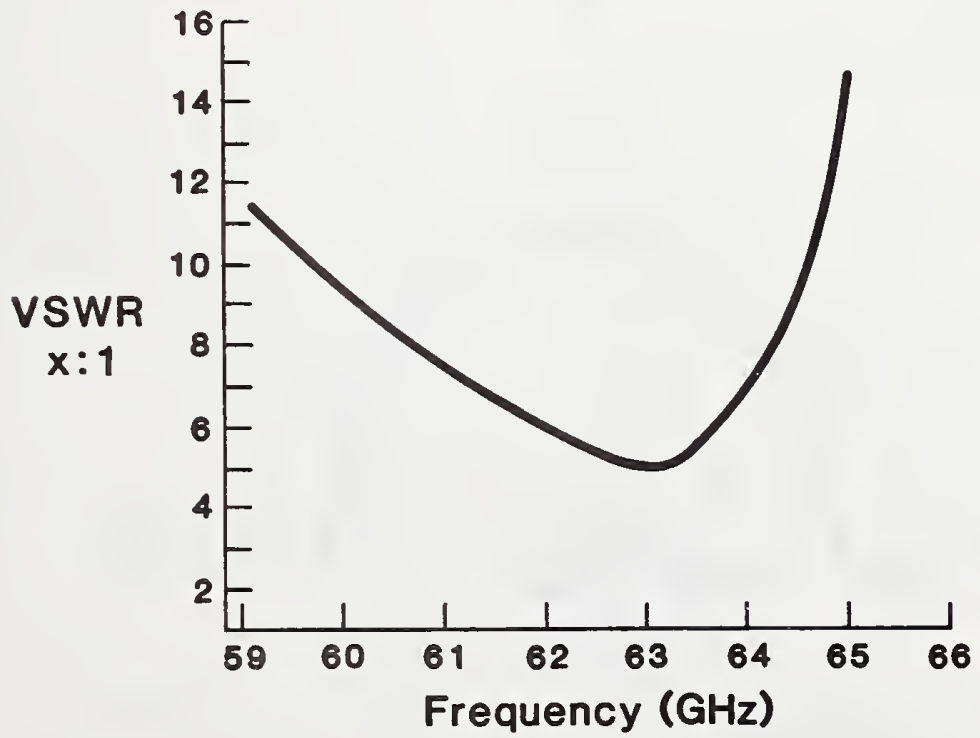

Figure 6. VSWR vs. frequency, antenna No. 1. 


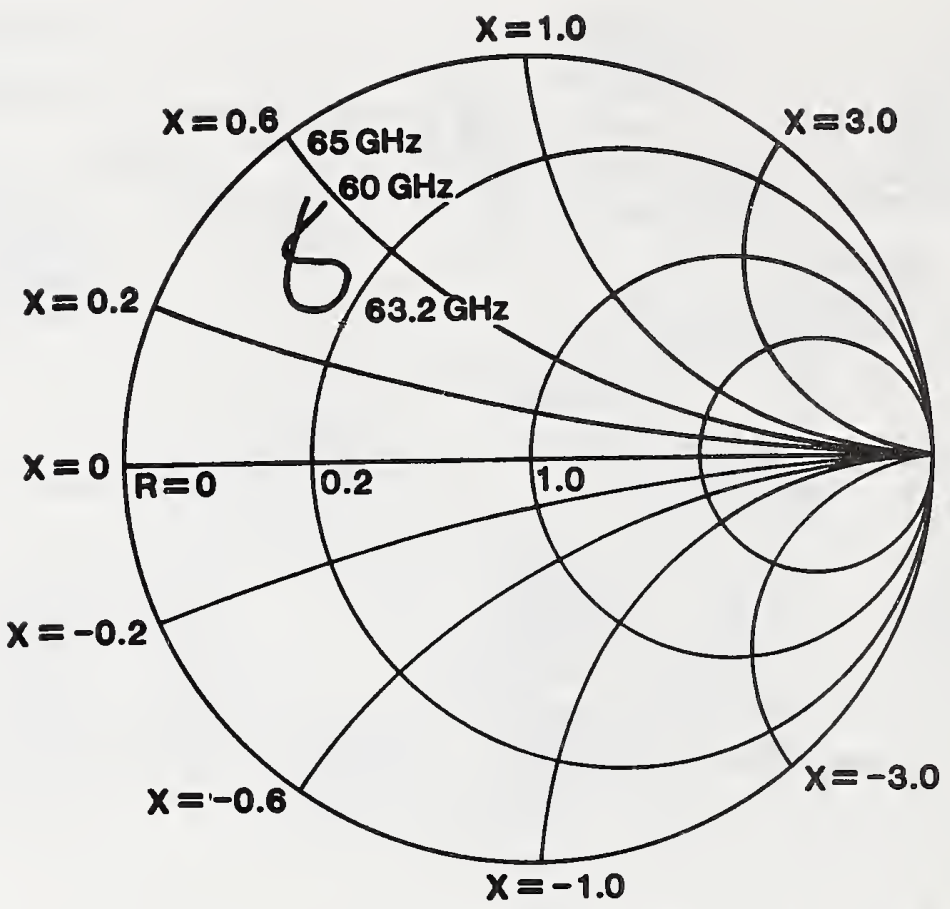

Figure 7. Input impedance, antenna No. 1.

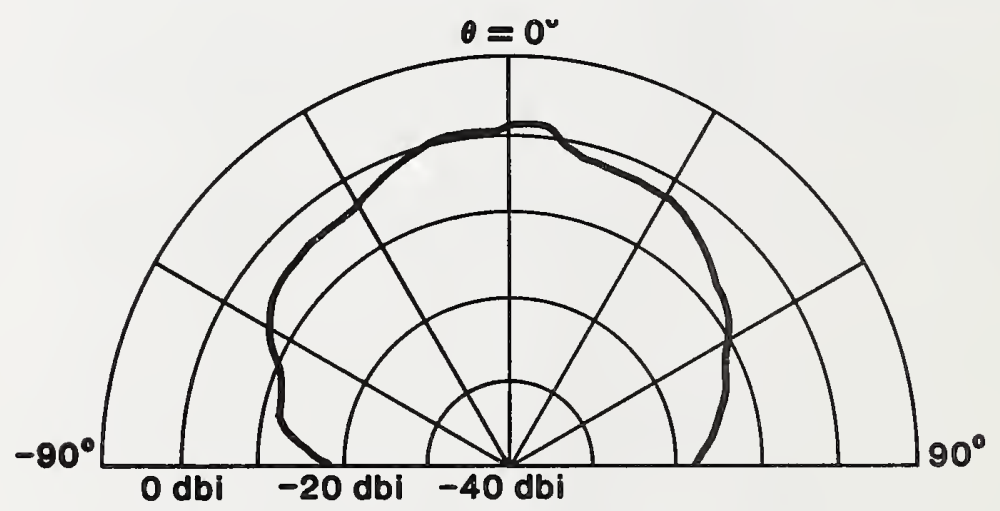

(a)

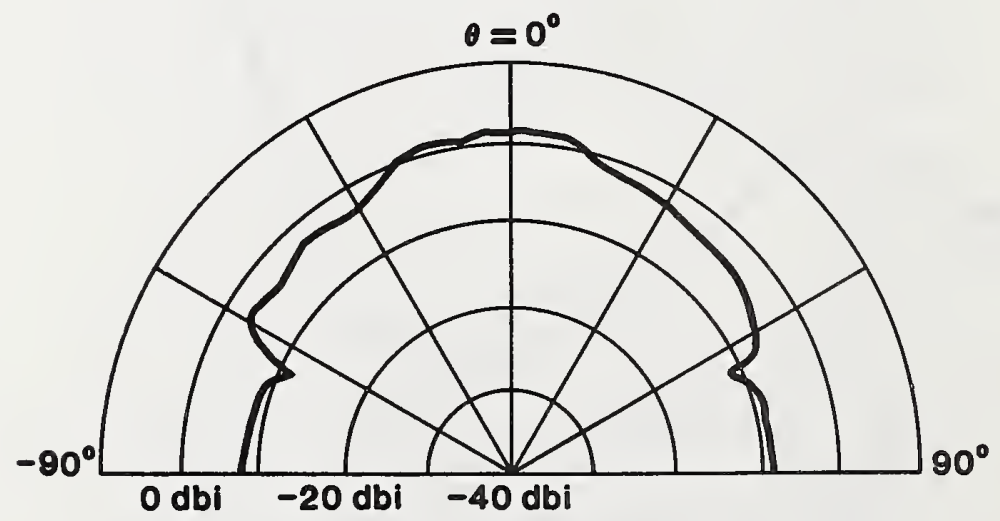

(b)

Figure 8. Far-field power pattern, antenna No. 1, $63.2 \mathrm{GHz}$.

(a) H-plane.

(b) E-plane. 


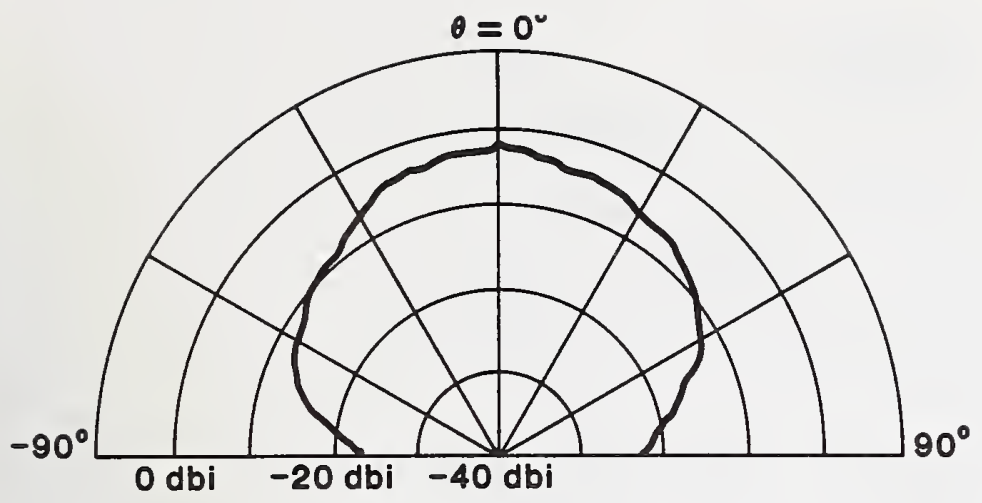

(a)

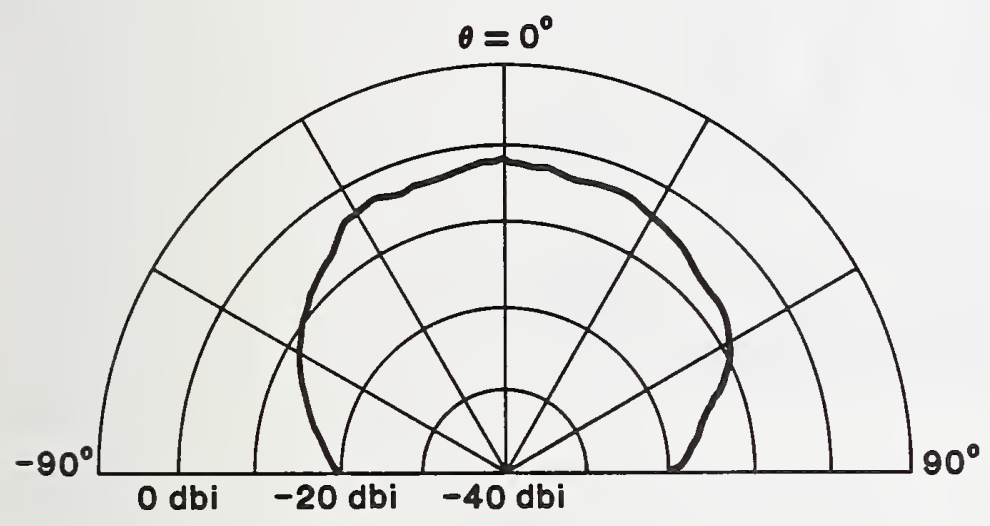

(b)

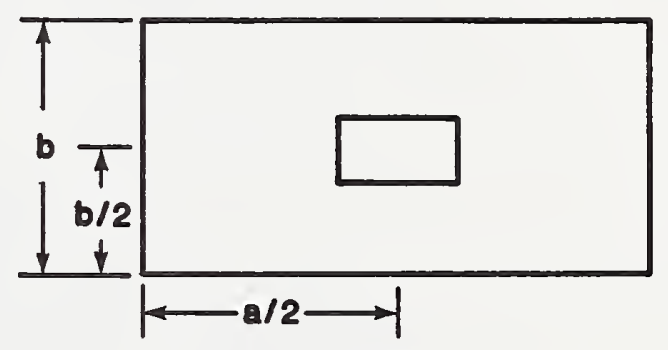

(a)
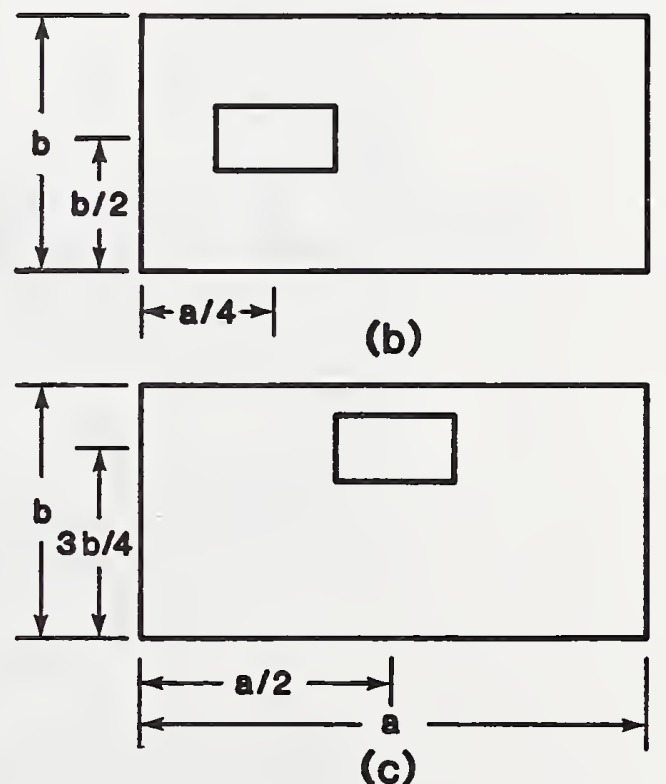

Figure 10. Iris-waveguide orientation.

(a) Antennas Nos. 1, 2, 3, 6, 7 . tern, antenna No. 1.

(a) $65.4 \mathrm{GHz}$.

(b) $59.2 \mathrm{GHz}$.

(b) Antenna No. 4.

(c) Antenna No. 5.

(c)

Figure 9. H-plane far-field power pat- 


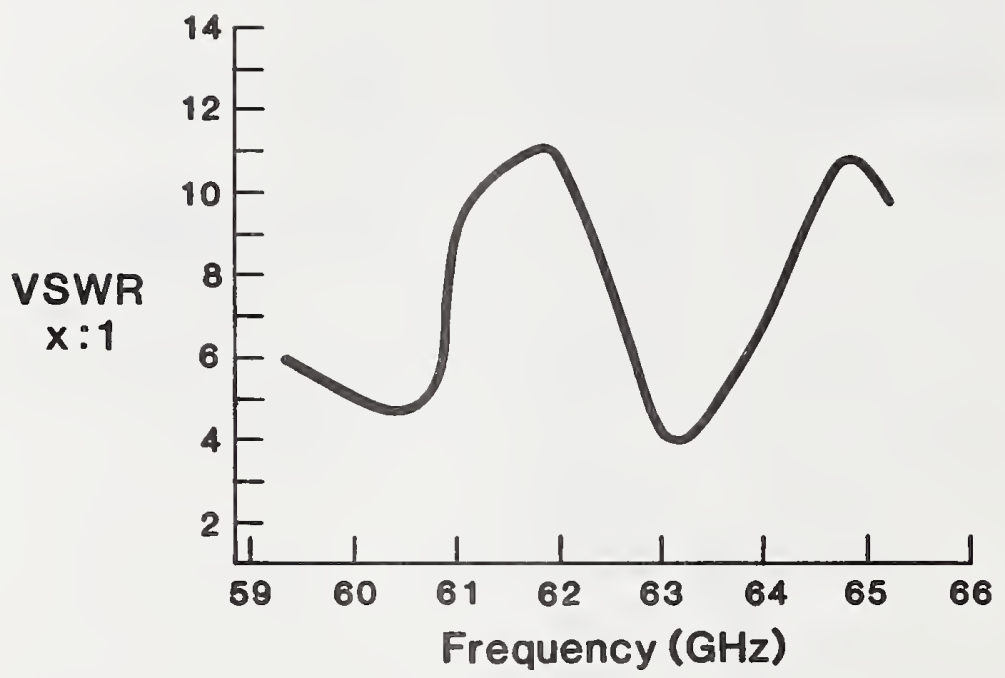

Figure 11. VSWR。 vs. frequency, antenna No. 2.

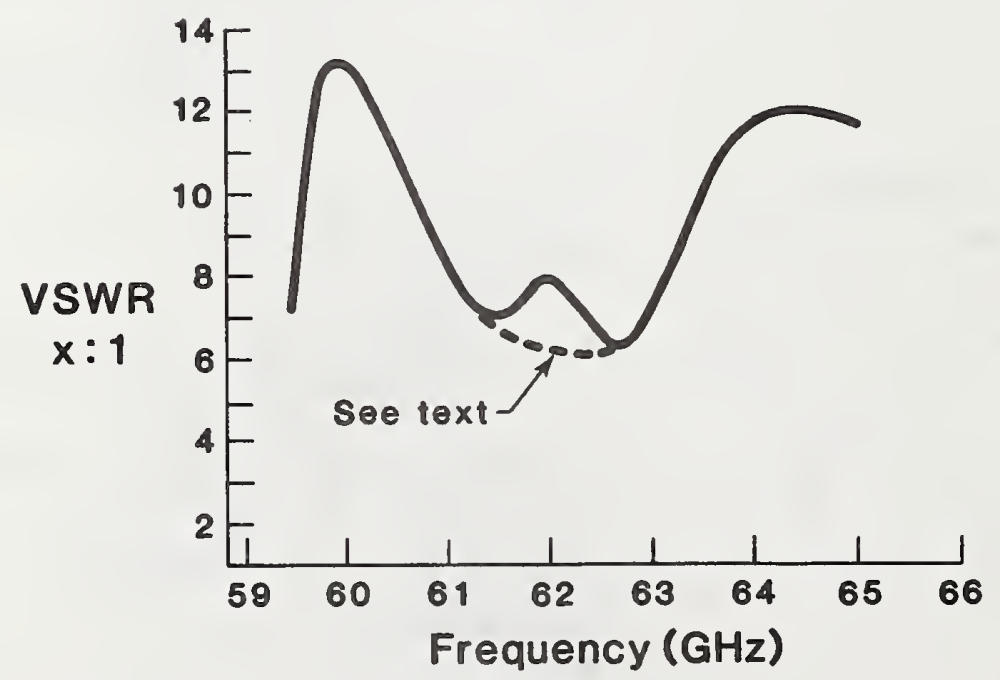

Figure 12. VSWR vs. frequency, antenna No. 3. 


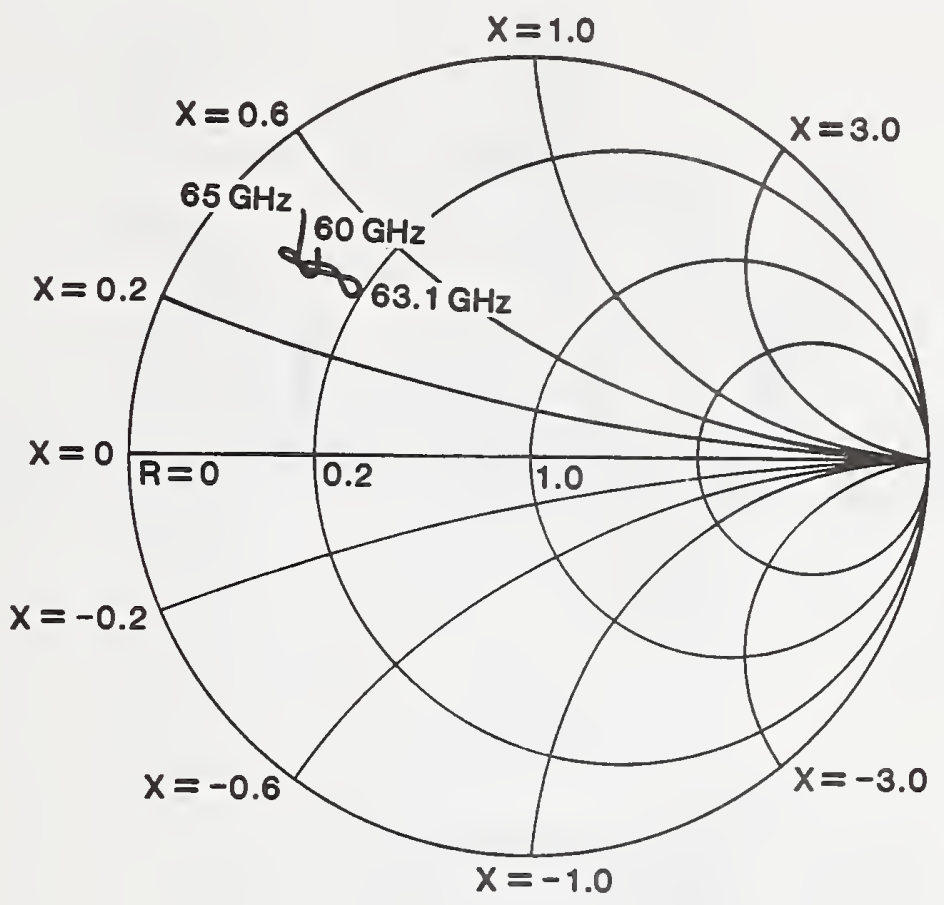

Figure 13. Input impedance, antenna No. 2.

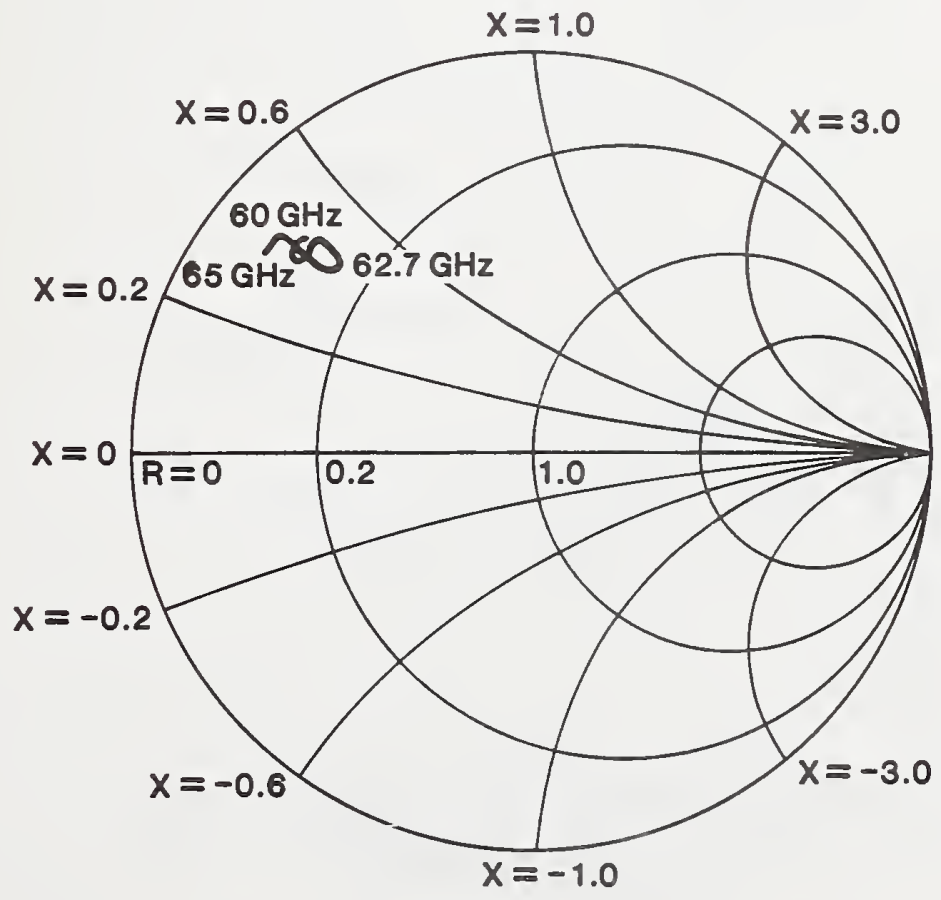

Figure 14. Input impedance, antenna No. 3. 


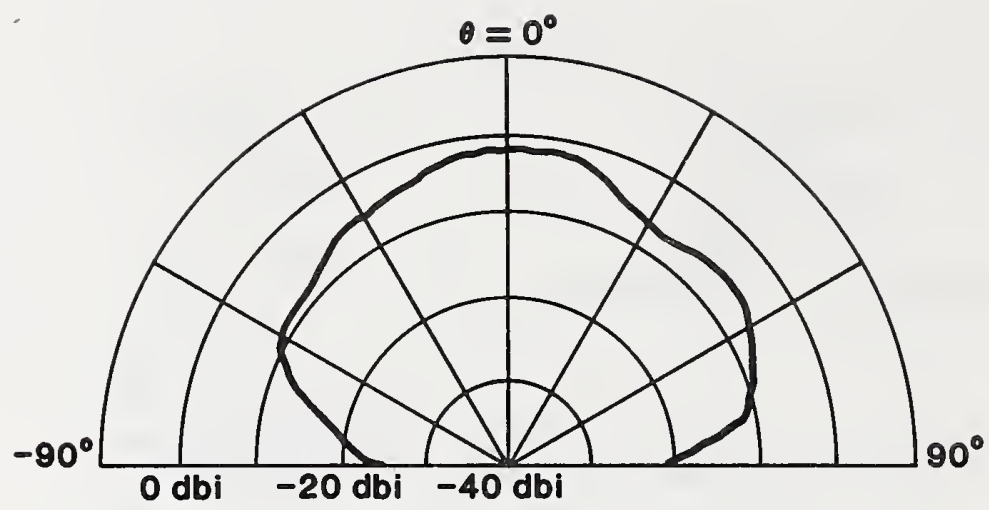

(a)

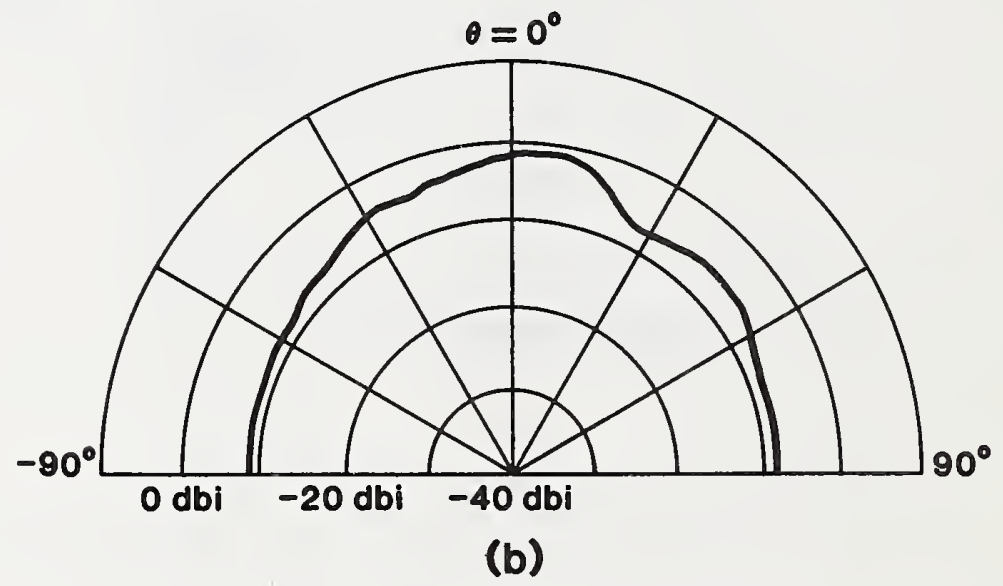

Figure 15. Far-field power pattern, antenna No. 3, 62.7 GHz.

(a) H-plane.

(b) E-plane.

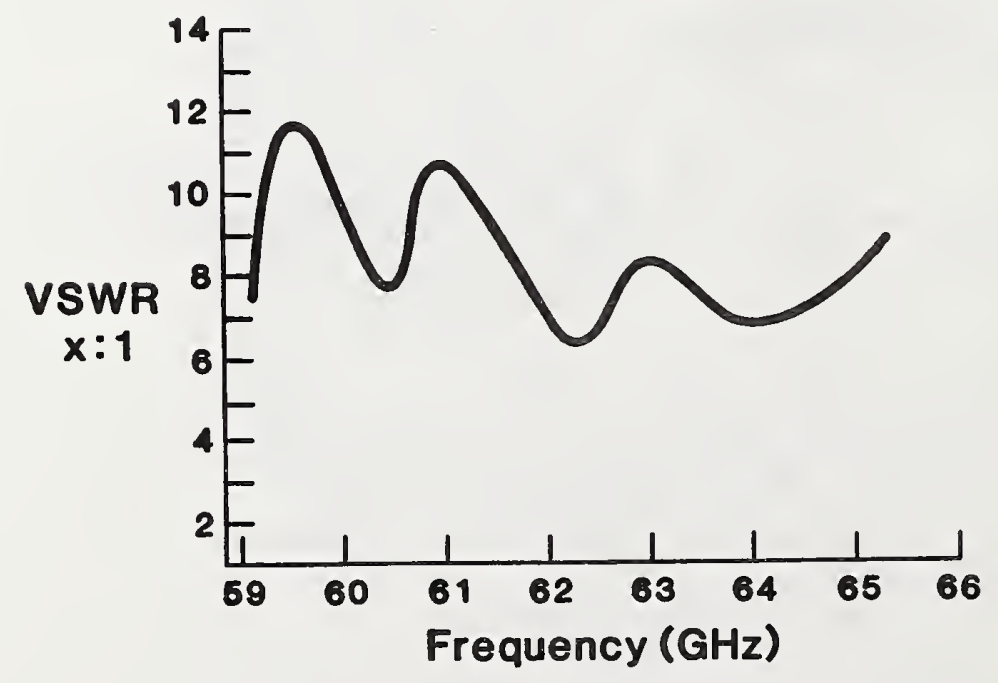

Figure 16. VSWR vs. frequency, antenna No. 4. 


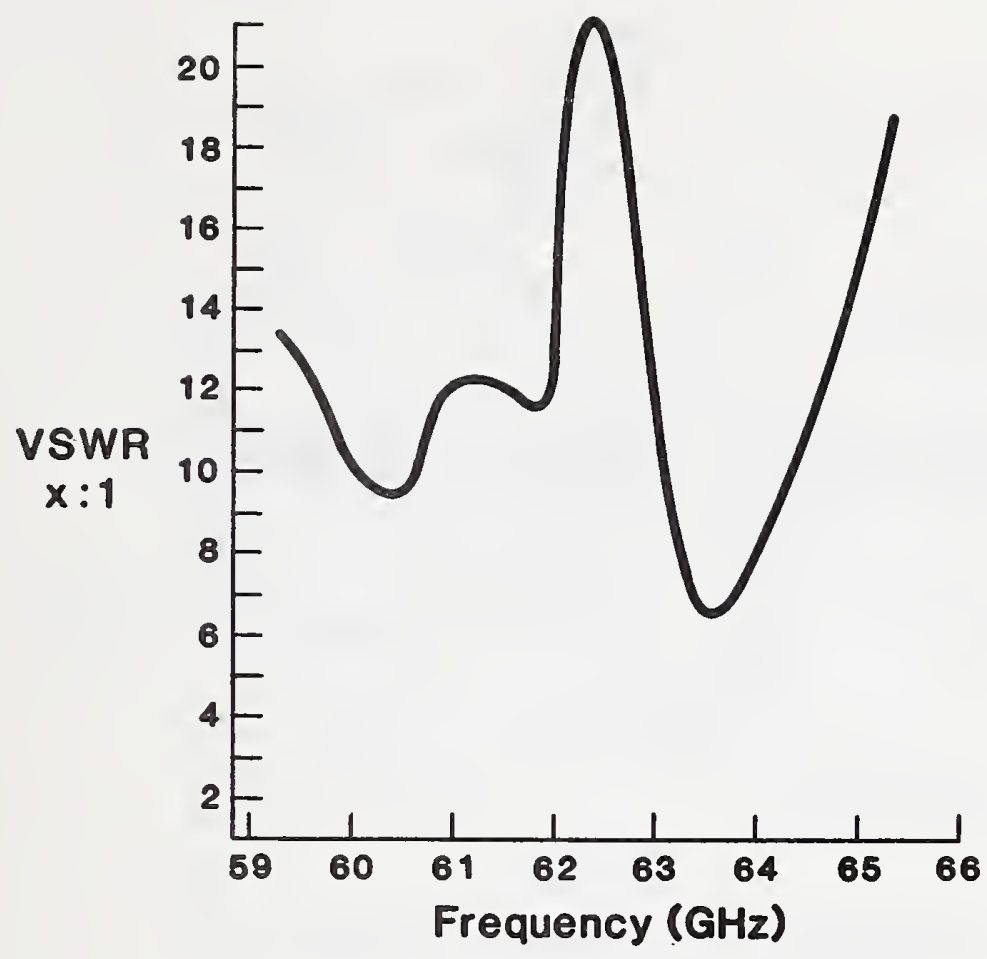

Figure 17. VSWR vs. frequency, antenna No. 5.

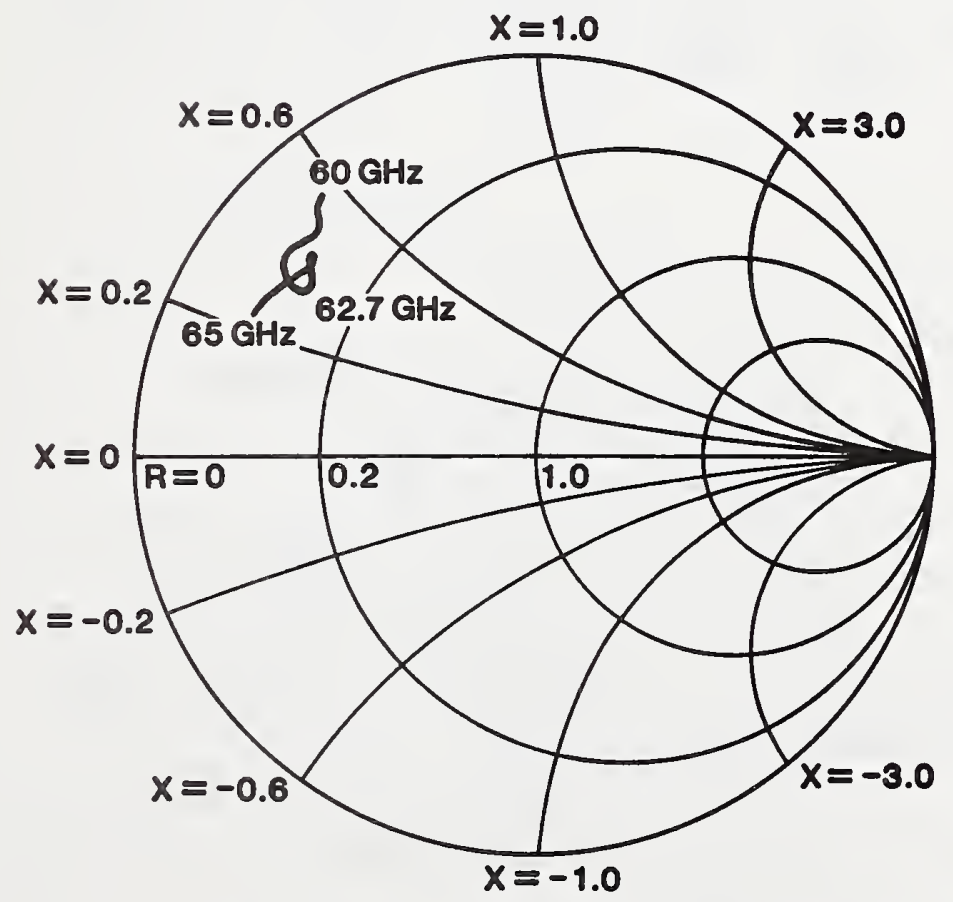

Figure 18. Input impedance, antenna No. 4. 


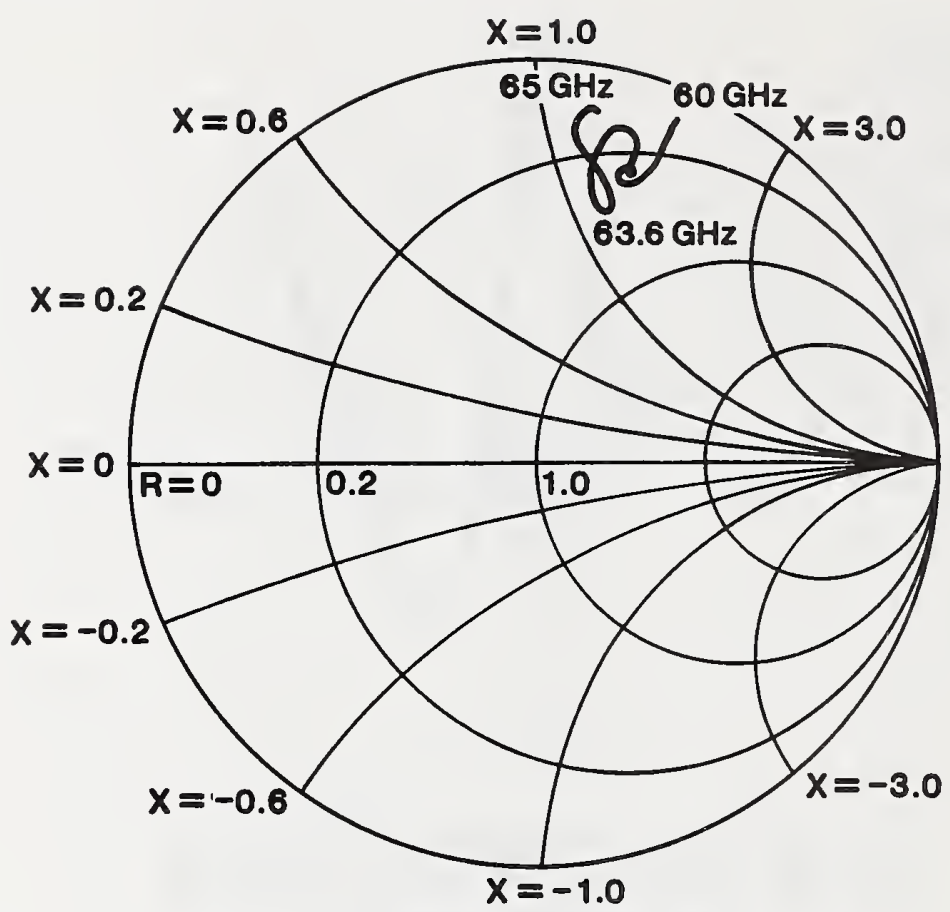

Figure 19. Input impedance, antenna No. 5.

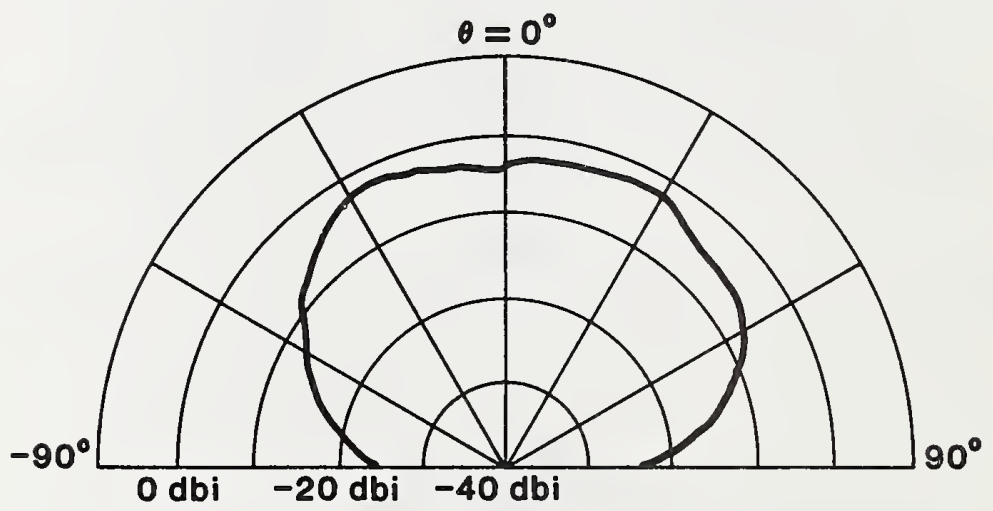

(a)

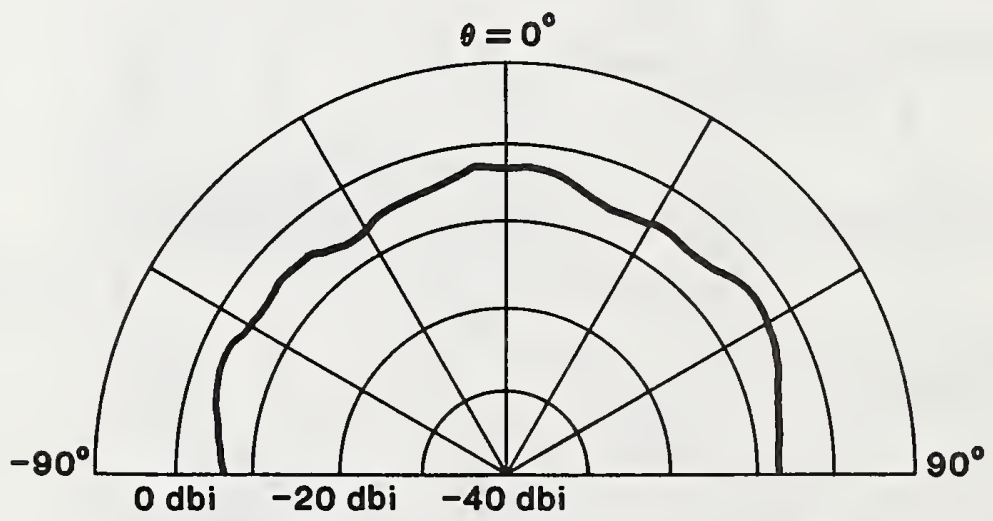

(b)

Figure 20. Far-field power pattern, antenna No. 4, $62.7 \mathrm{GHz}$.

(a) H-plane.

(b) E-plane. 


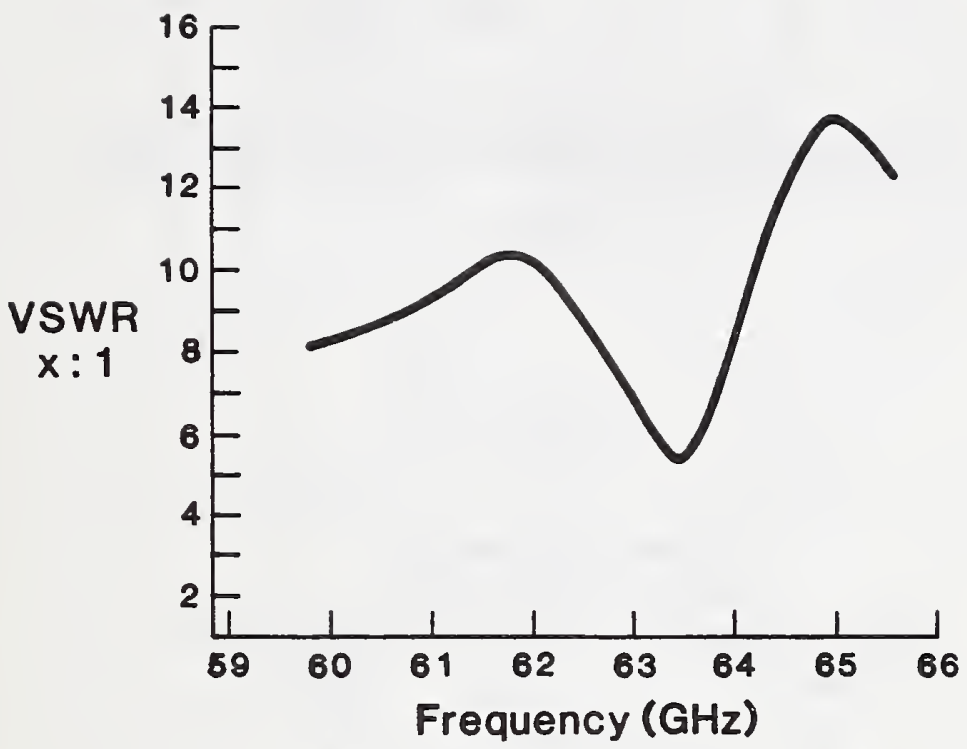

Figure 21. VSWR vs. frequency, antenna No. 6.

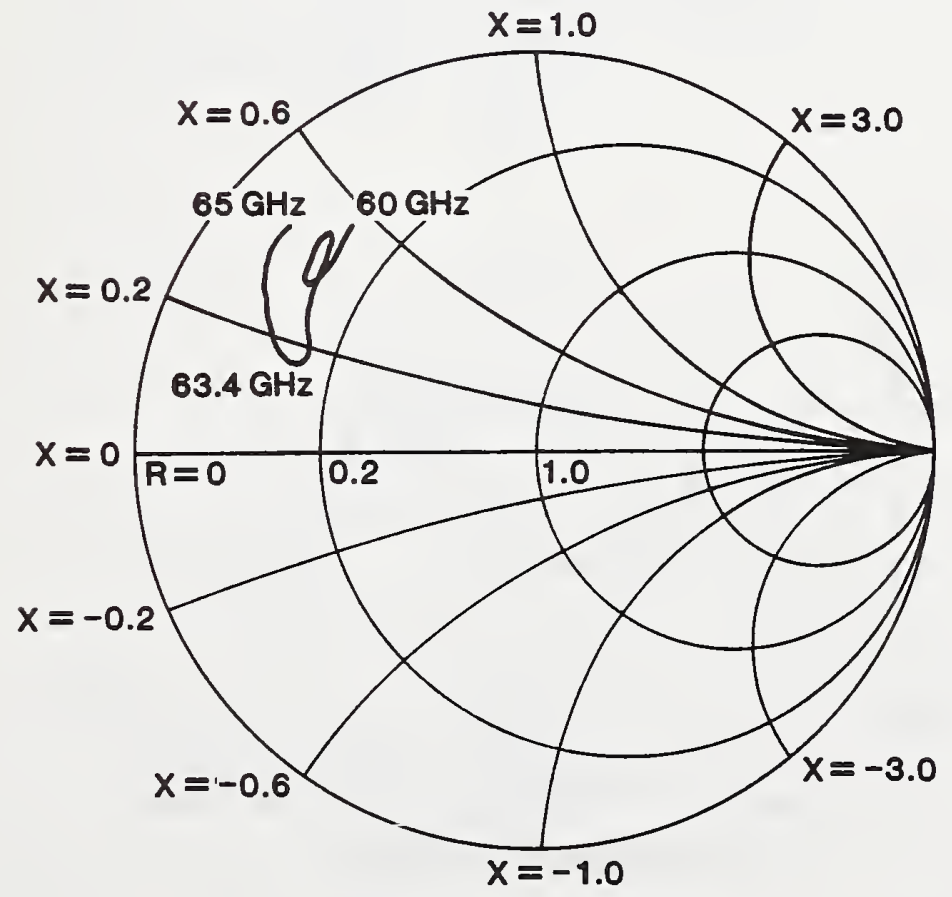

Figure 22. Input impedance, antenna No. 6 . 


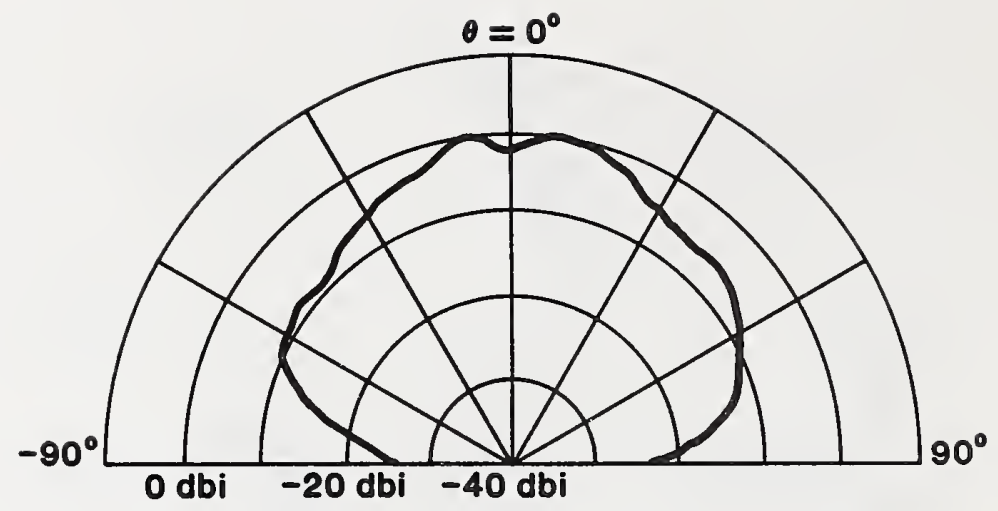

(a)

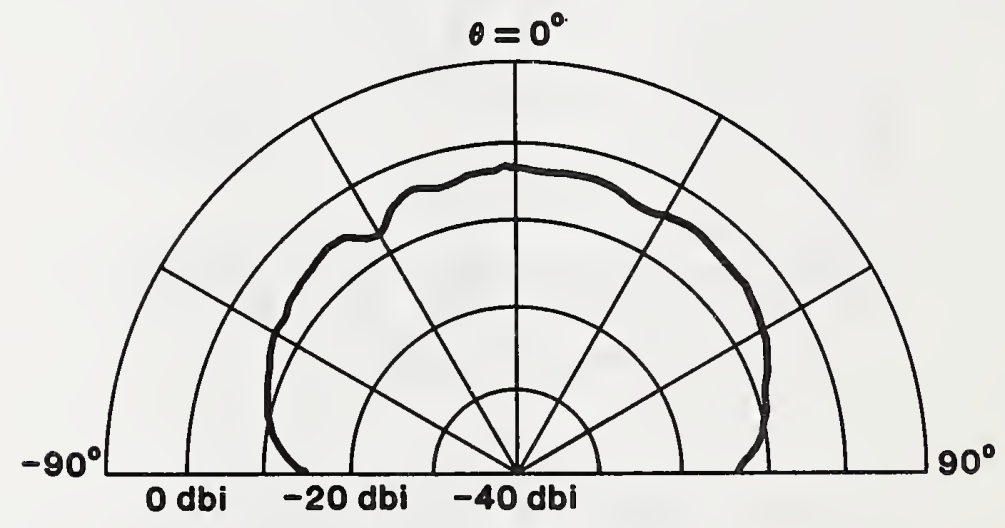

(b)

Figure 23. Far-field pattern, antenna No. $6,63.4 \mathrm{GHz}$.

(a) H-plane.

(b) E-plane.

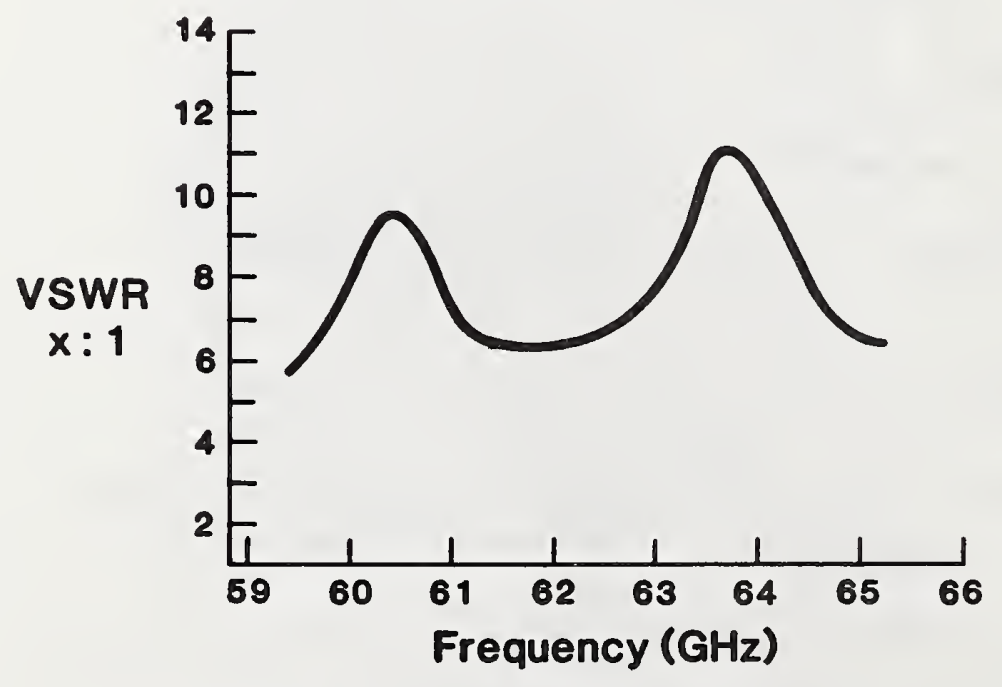

Figure 24. VSWR vs. frequency, antenna No. 7. 


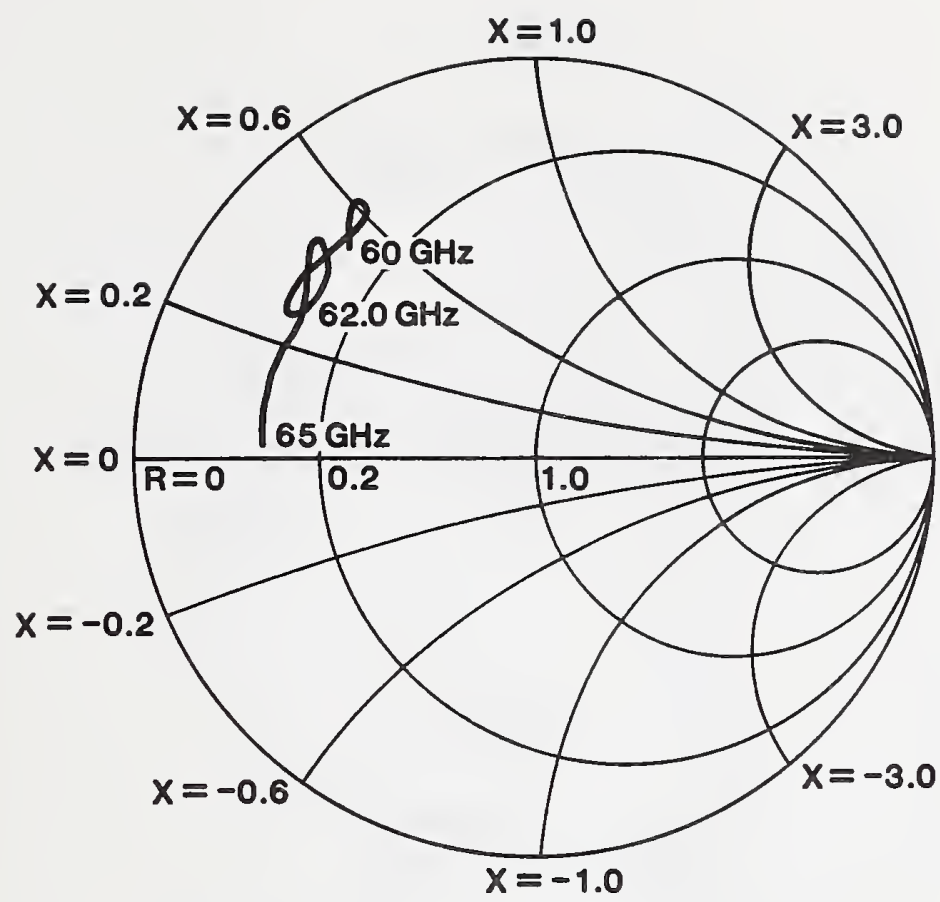

Figure 25. Input impedance, antenna No. 7.

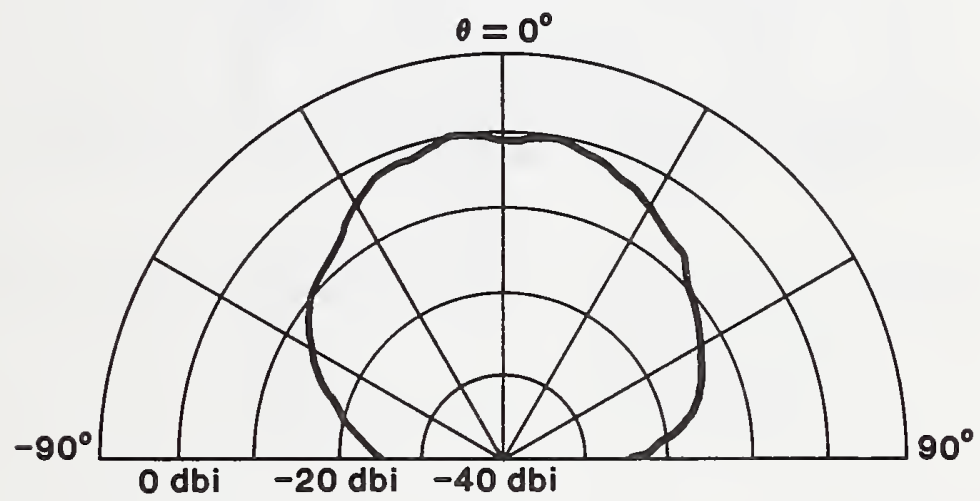

(a)

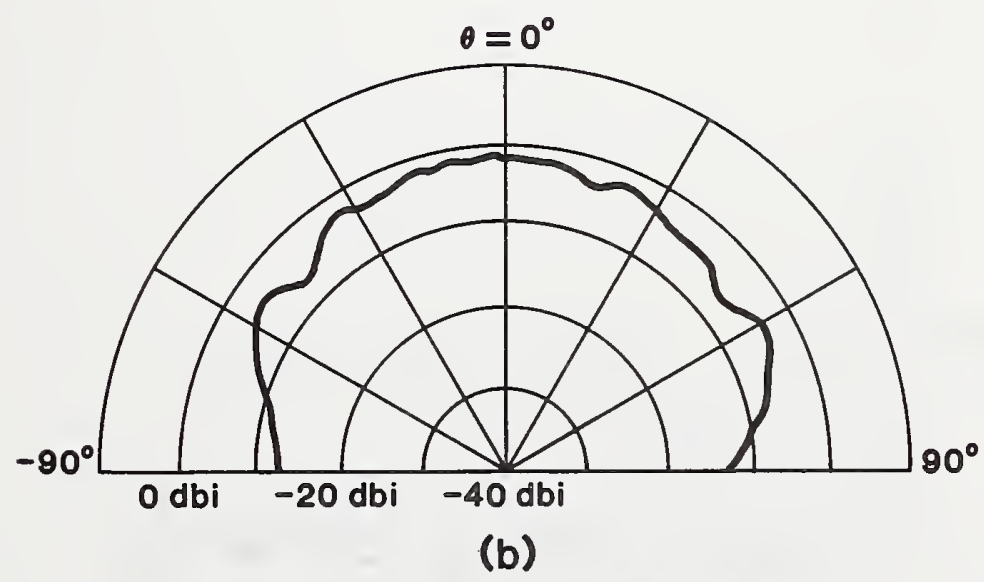

Figure 26. Far-field power pattern, antenna No. 7, $62.0 \mathrm{GHz}$.

(a) H-plane.

(b) E-plane. 


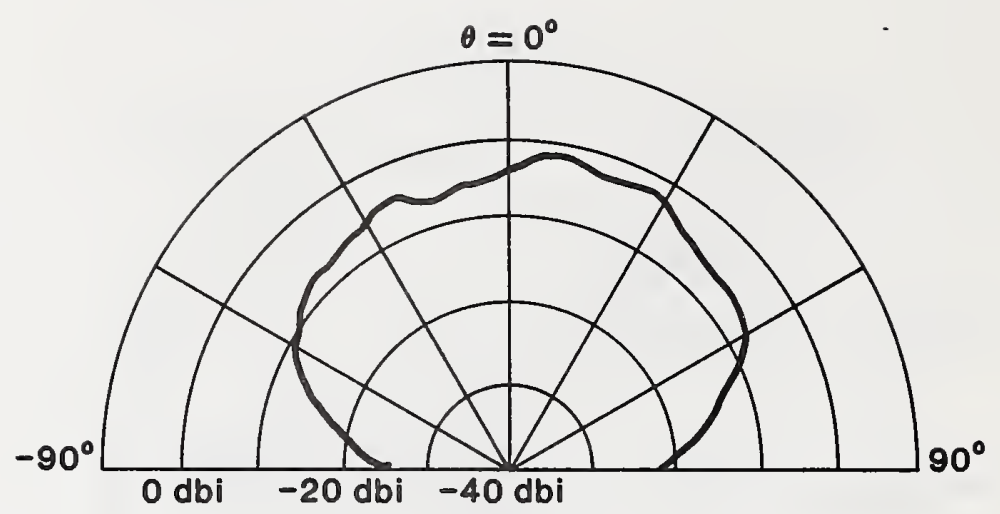

(a)

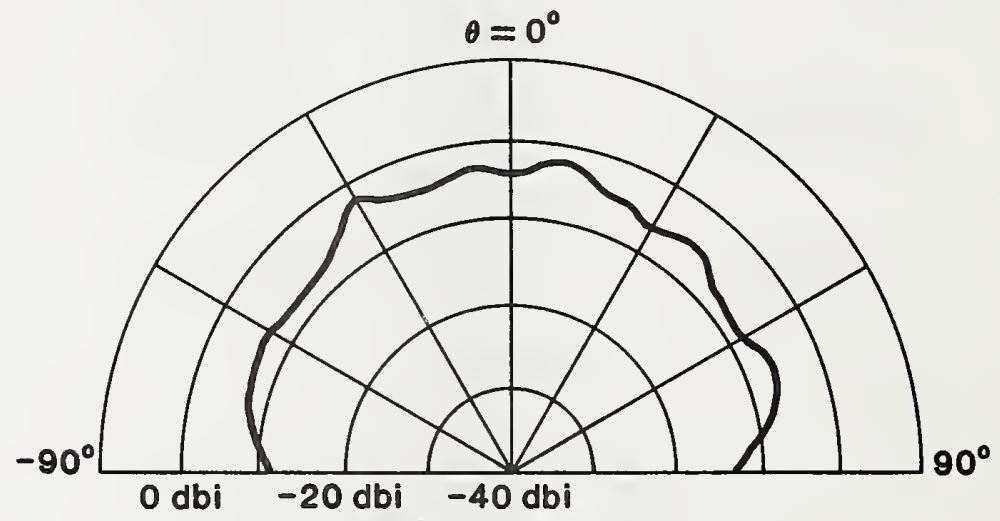

(b)

Figure 27. Far-field power pattern, antenna No. 7, $65.1 \mathrm{GHz}$.

(a) $\mathrm{H}$-plane.

(b) E-plane.

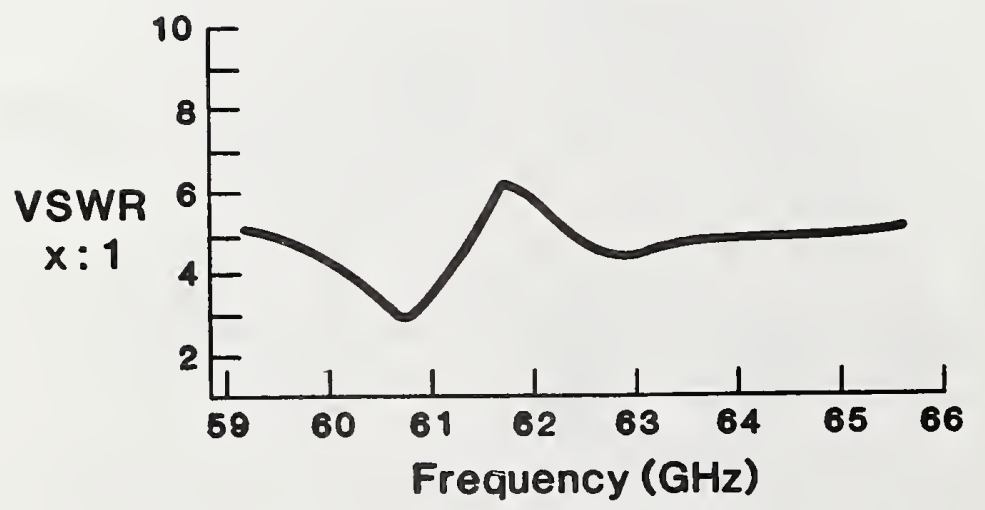

Figure 28. VSWR vs. frequency, antenna No. 8. 


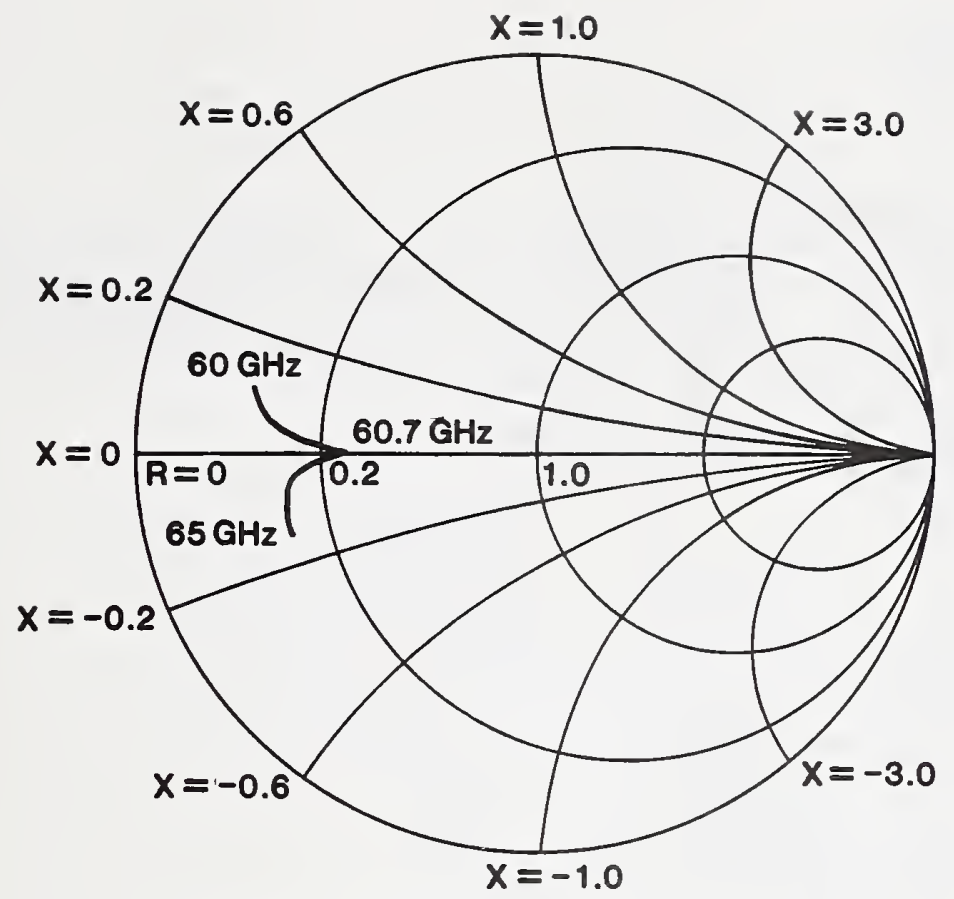

Figure 29. Input impedance, antenna No. 8.

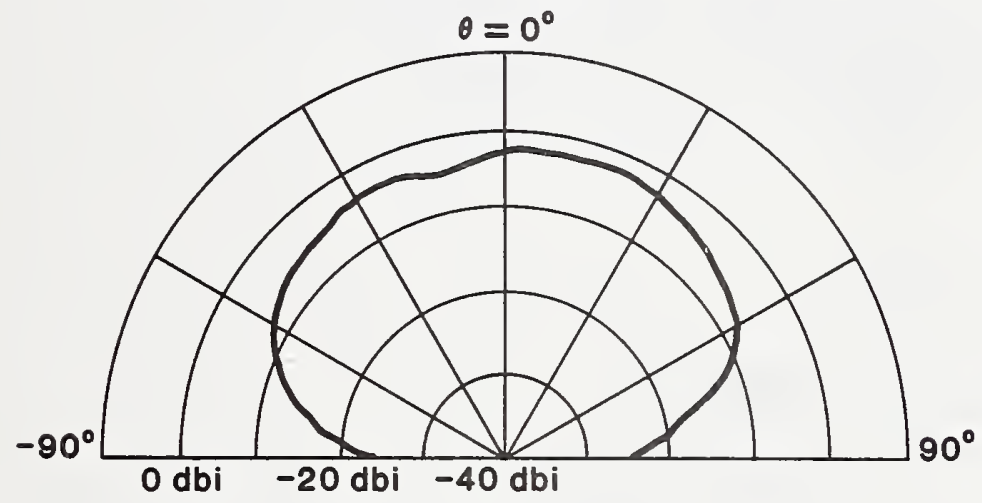

(a)

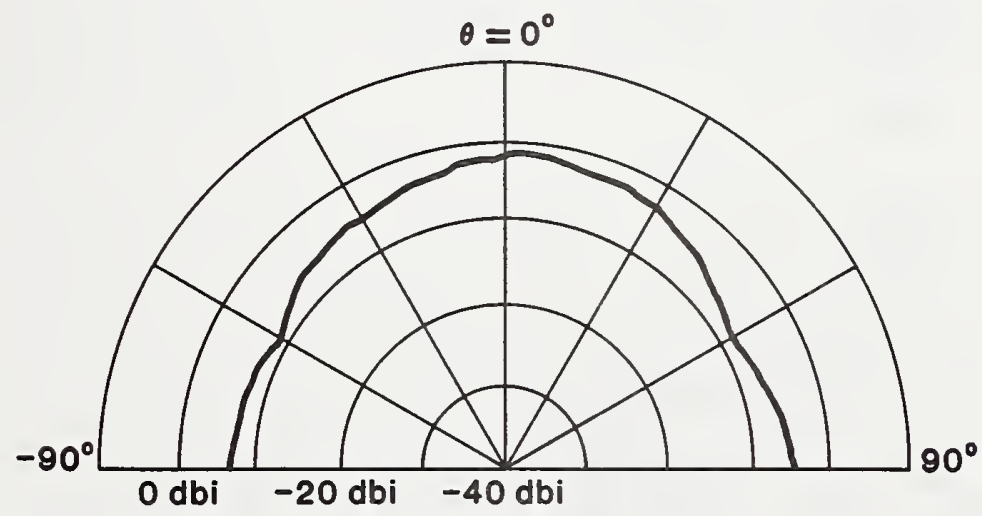

(b)

Figure 30. Far-field power pattern, antenna No. 8, 60.7 G Hz.

(a) H-plane.

(b) E-plane. 


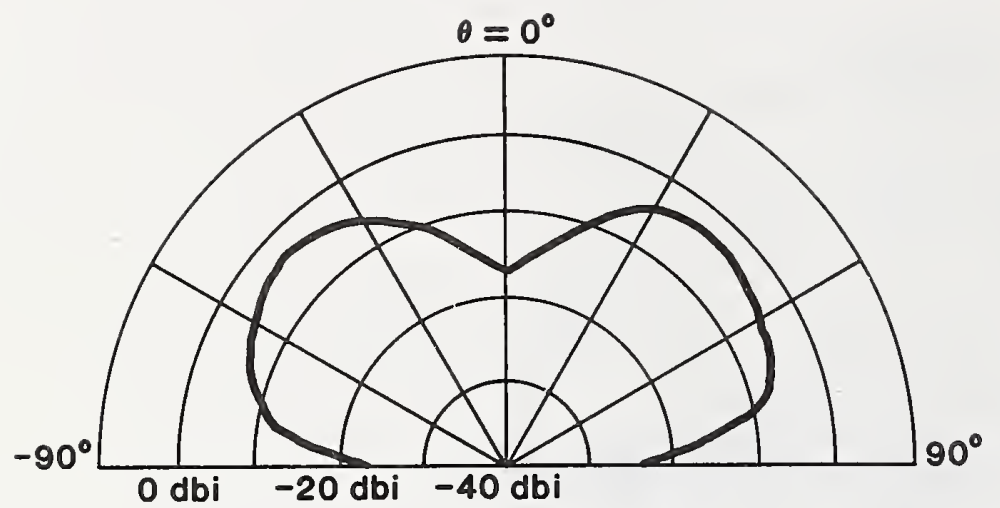

(a)

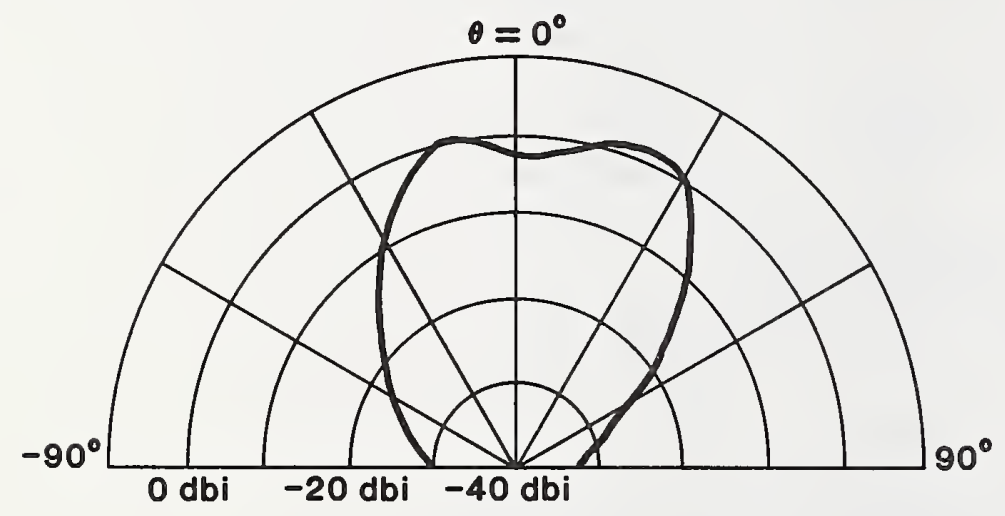

(a)

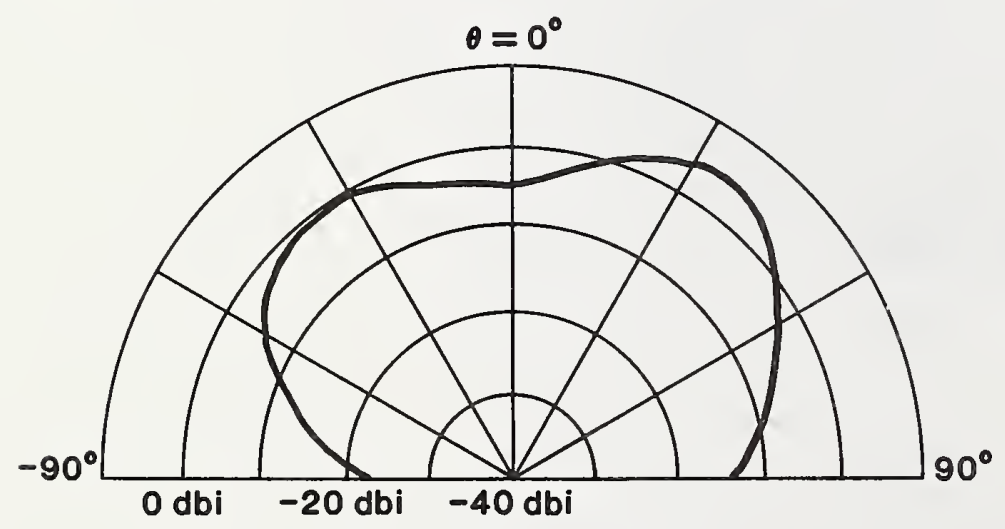

(b)

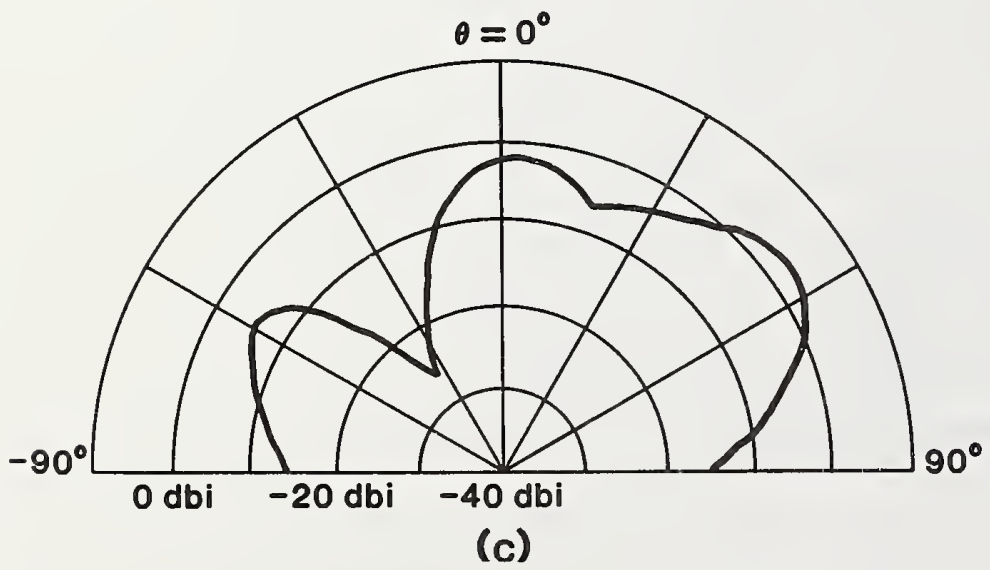

Figure 31. H-plane far-field power pattern, antenna No. $8,65.3 \mathrm{GHz}$.
Figure 32. H-plane far-field power pattern, antenna No. 8, off-centered 0.8 $\mathrm{mm}$ in $+x$-direction.
(a) $60.7 \mathrm{GHz}$.
(b) $63.4 \mathrm{GHz}$.
(c) $65.3 \mathrm{GHz}$. 


\section{Appendix A}

\section{Far-Field Positioner and Slotted Line Drawings}

On the following pages drawings of the far-field spherical positioner (fig. Al through fig. A3) and of the slotted line (fig. A4 through fig. A9) are presented. Certain non-critical dimensions have been omitted such as dimensions for set screw holes. 


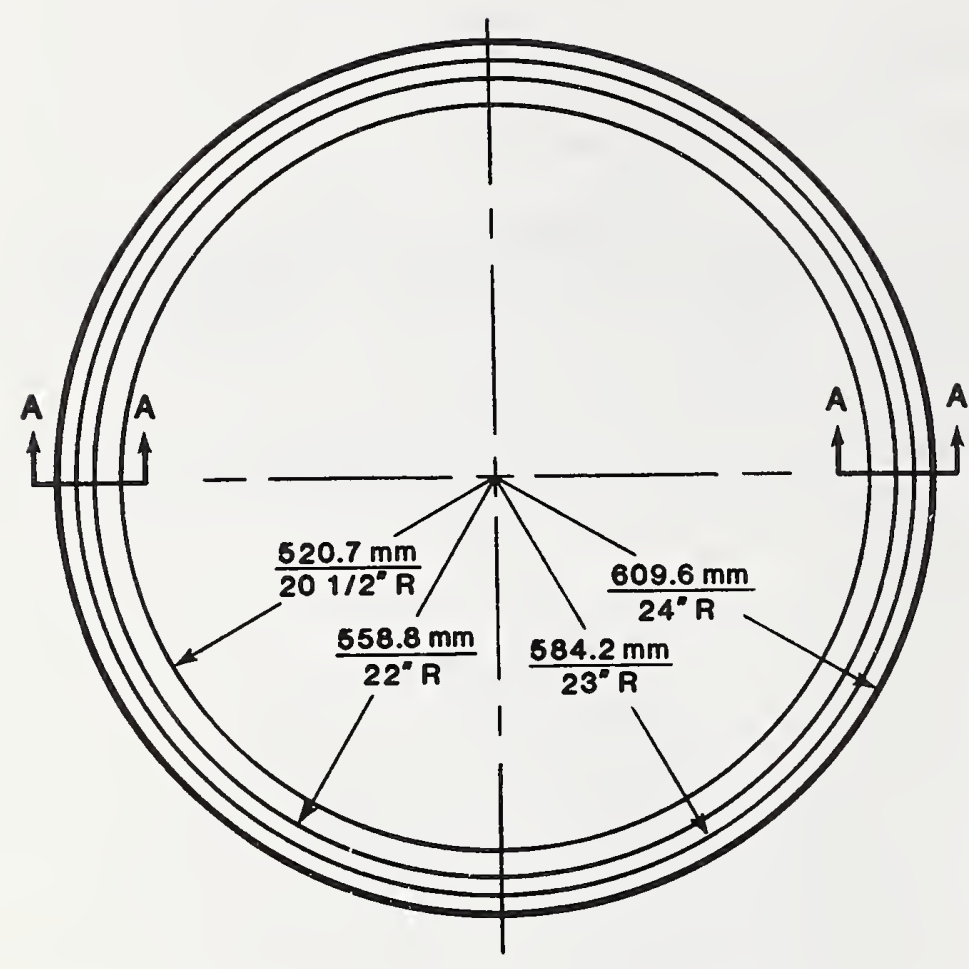

Figure Al. Baseplate of spherical posi-

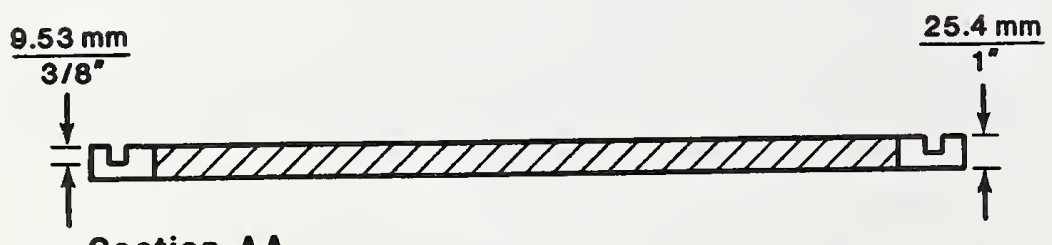

Section AA

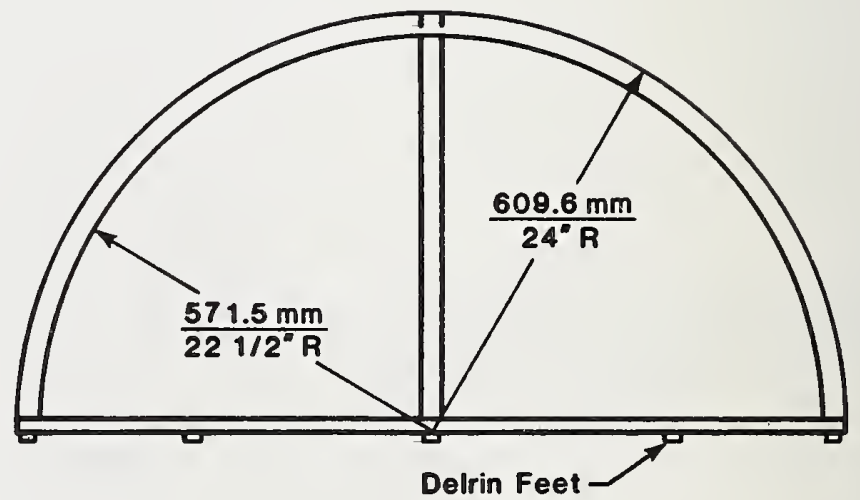

Figure A2. Elevation position arm of spherical positioner.

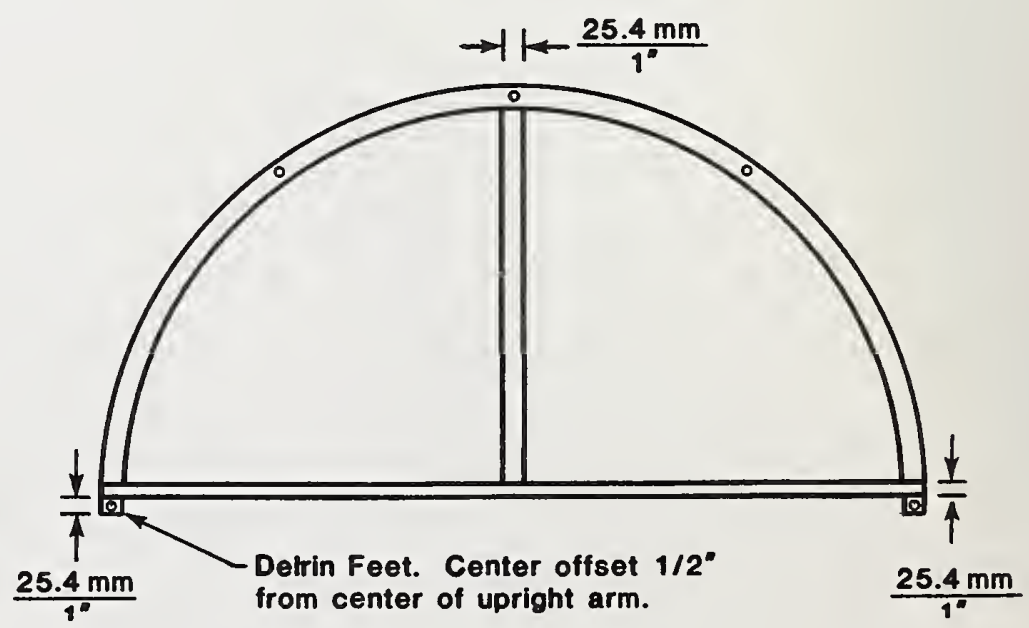




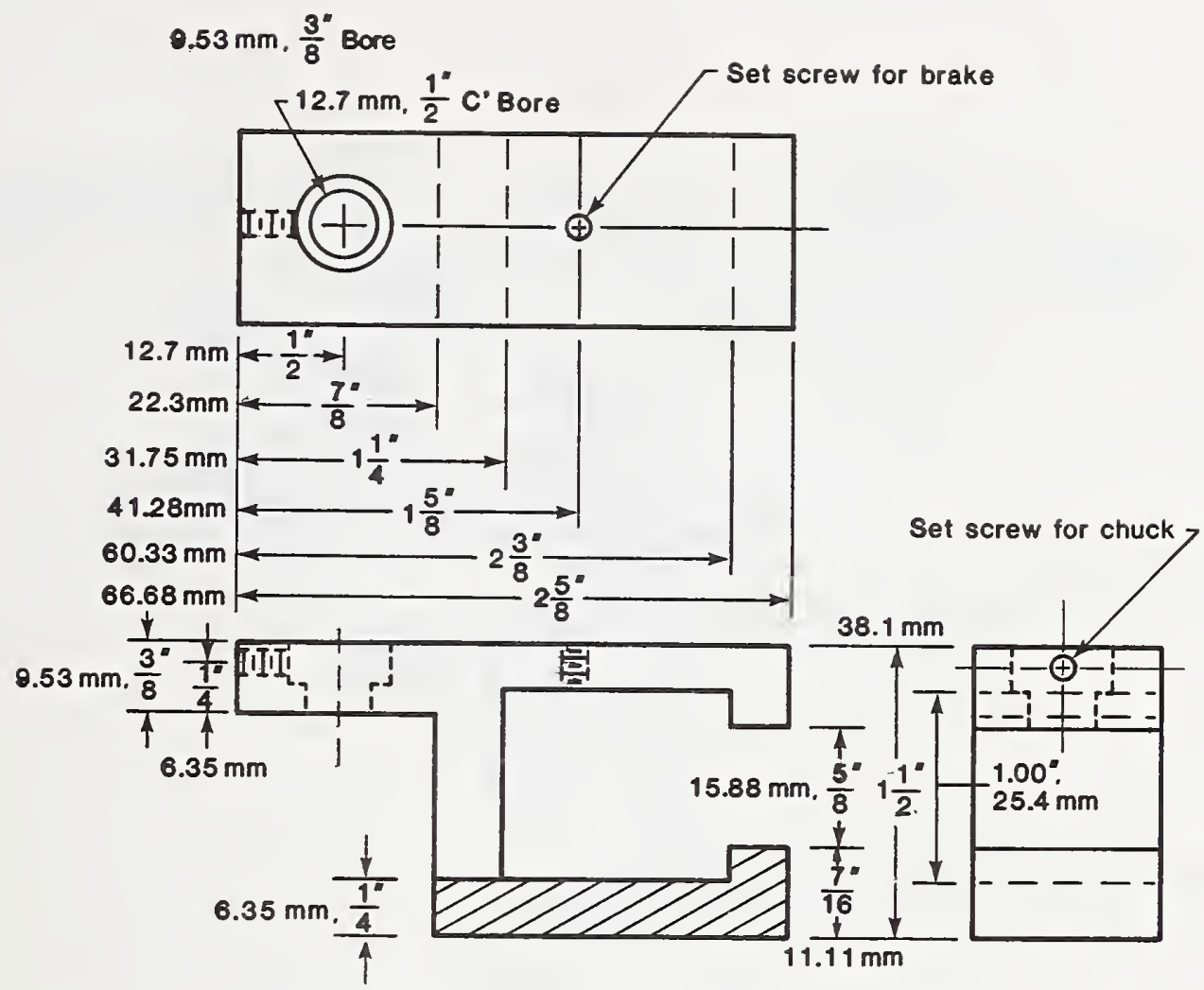

Figure A3. Receiving antenna mounting bracket for spherical positioner.

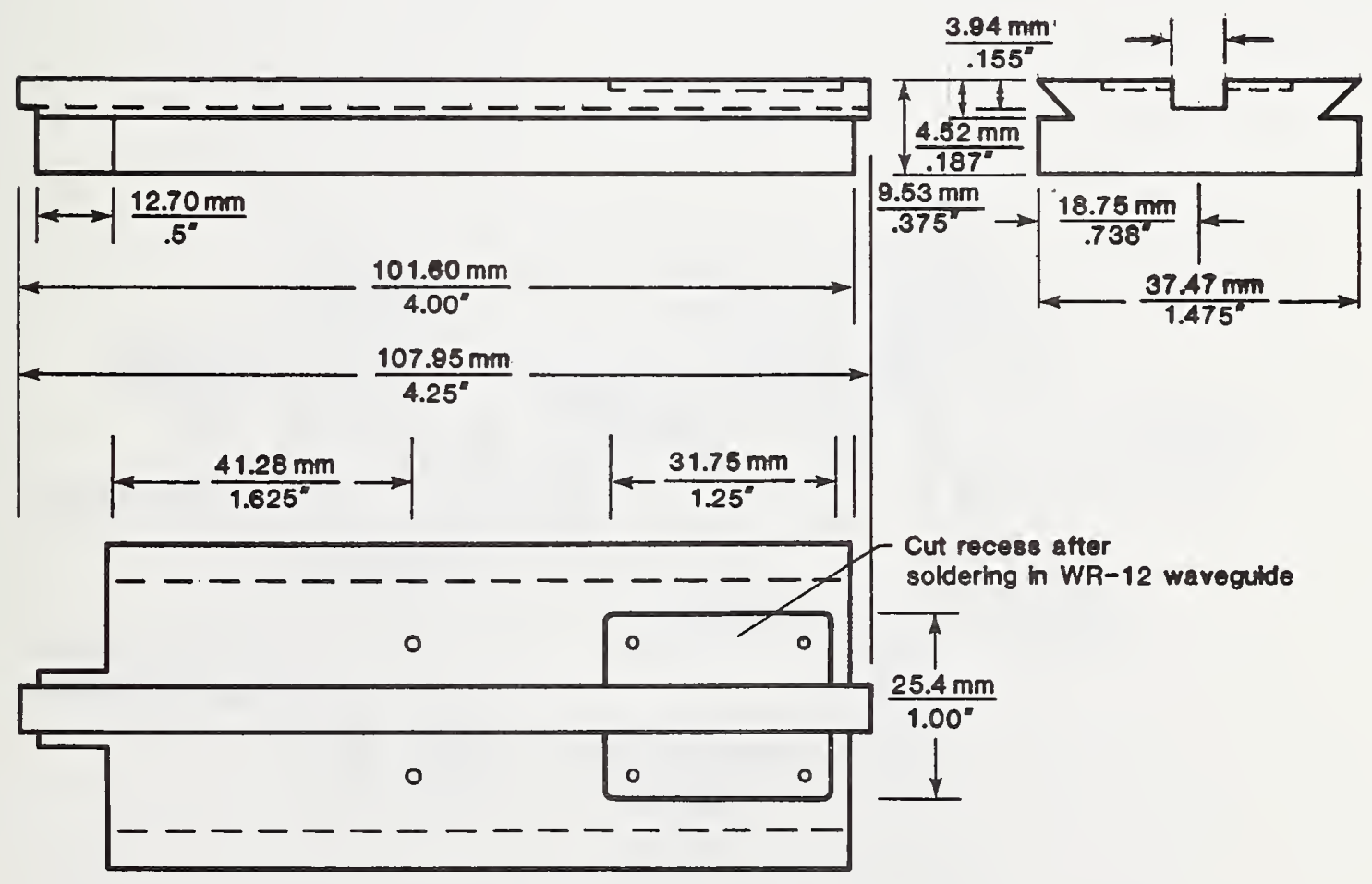

Figure A4. Slotted line baseplate. 


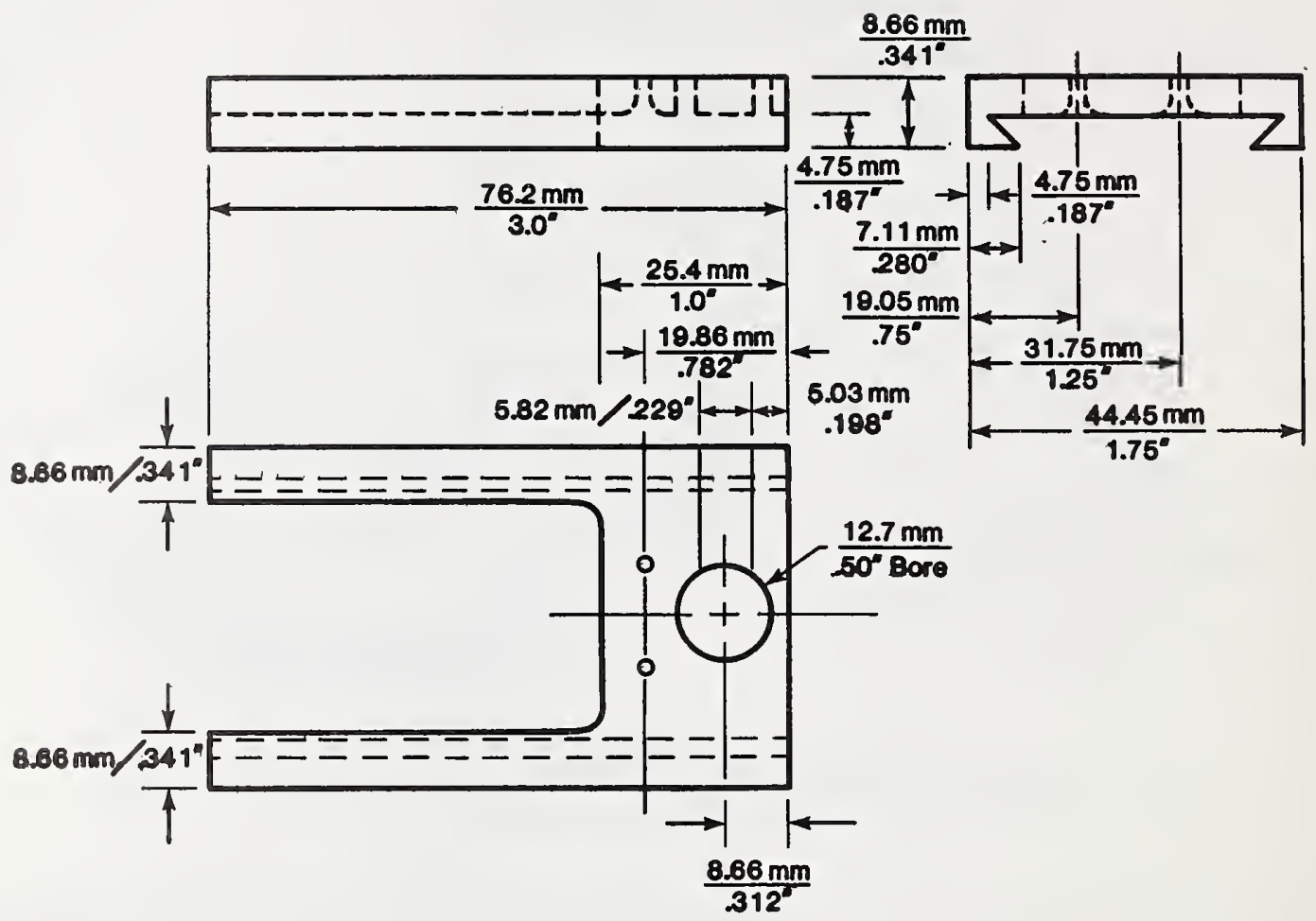

Figure A5. Slotted line sliding section.

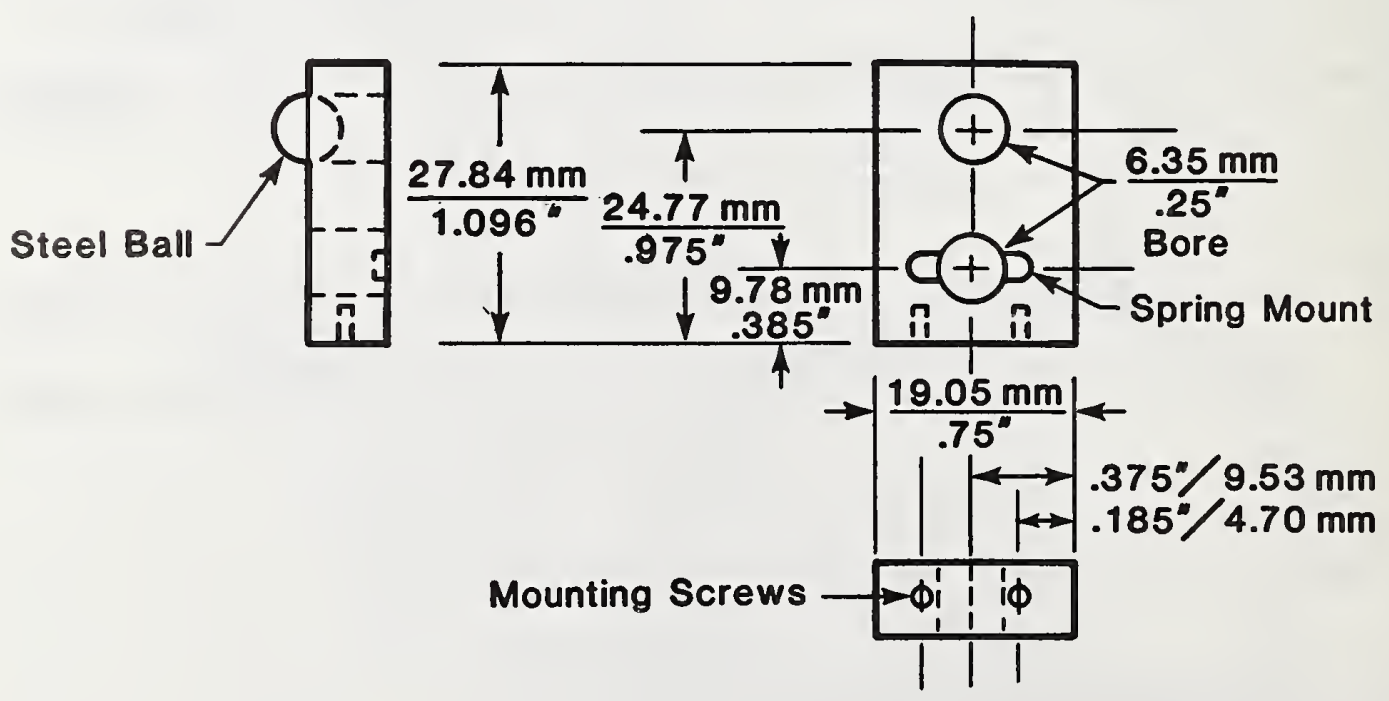

Figure A6. Slider pusher assembly. 


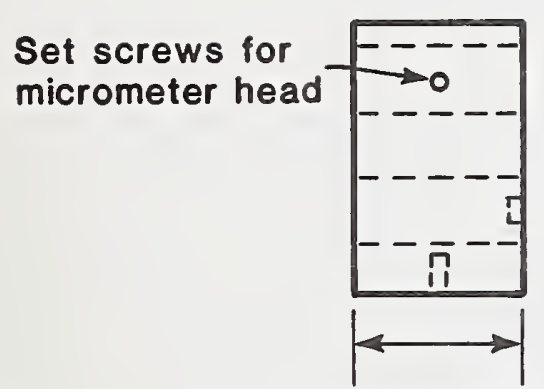

$14.99 \mathrm{~mm}$

$.59^{\prime \prime}$

Dimensions as for Fig. A6 except as noted.

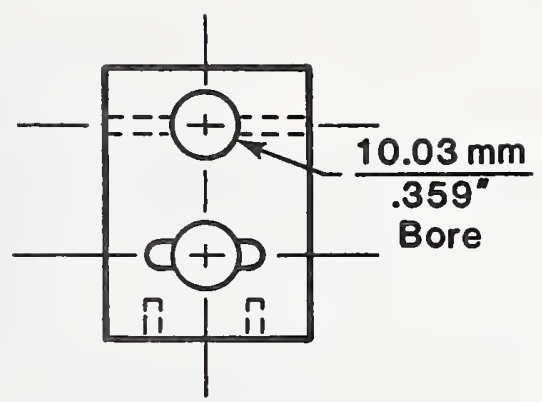

Figure A7. Micrometer mount for slotted line.
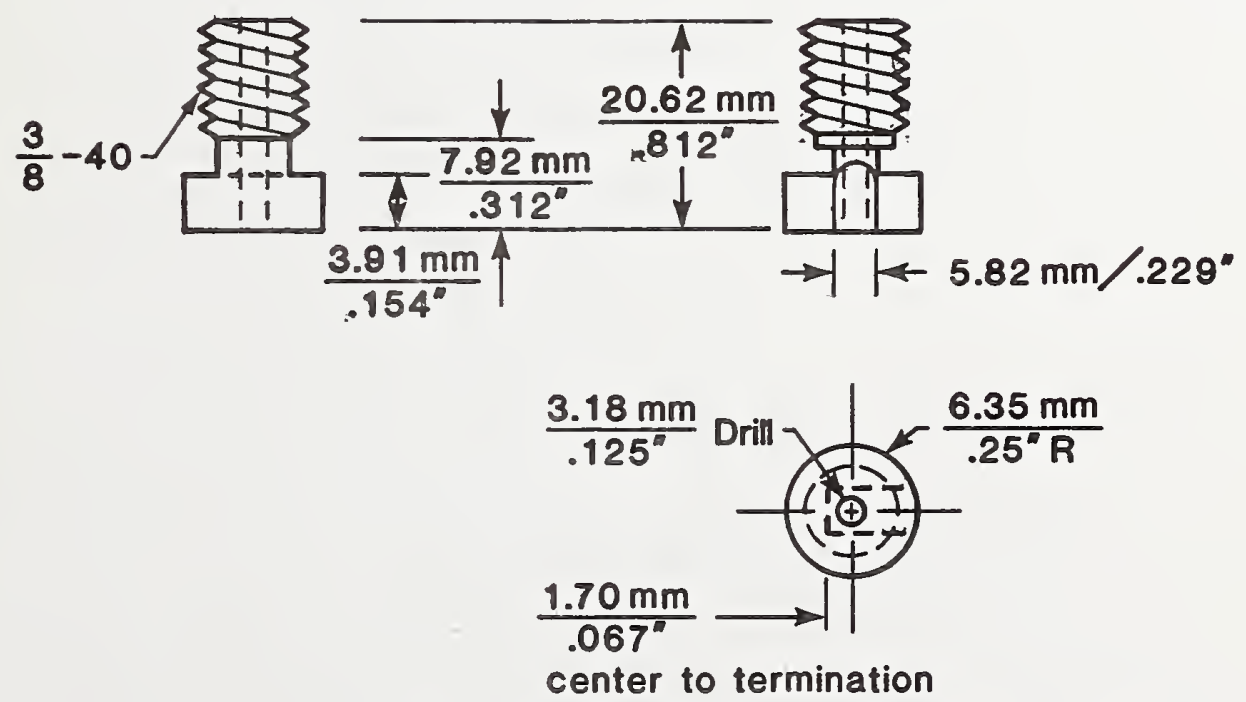

Figure A8. Pick-up waveguide termination and probe mour.t sleeve. 


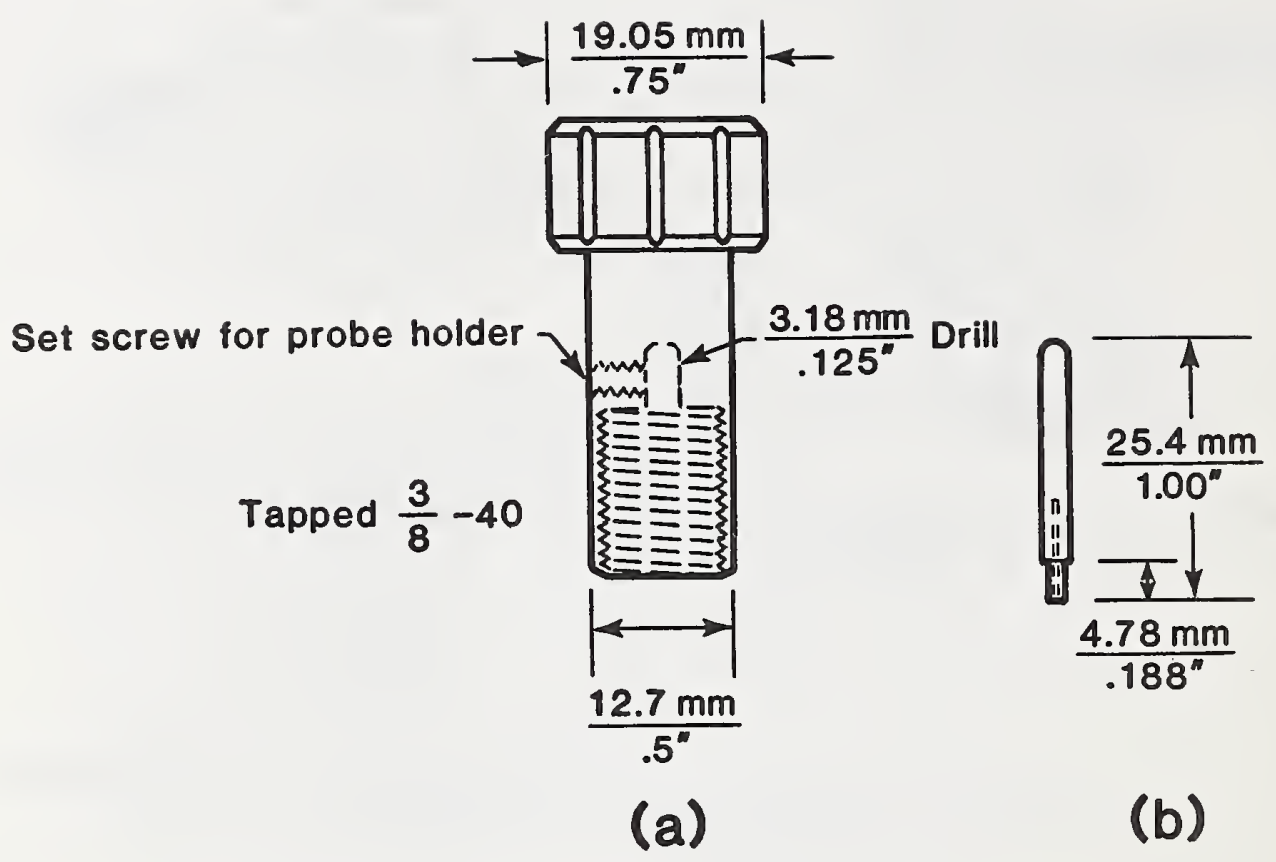

Figure A9. (a) Probe adjustment screw.

(b) Kel-f probe holder. 
Initial Investigation of the Longitudinal Feed

An initial investigation was made into the iris-fed rectangular microstrip patch antenna fed from the longitudinal wall of the source waveguide. The patch, constructed on the material $(\varepsilon=2.20)$, was identical in size to the patches of antennas No. 2 through No. 7 . Thus, the predicted resonant frequency was $62.8 \mathrm{GHz}$ eq (21). The iris, centered with respect to the patch, was of dimensions $D=$ $0.372 \mathrm{~mm}$ and $d=0.725 \mathrm{~mm}$.

One of the two wider walls of the WR-12 waveguide was milled away. In its place the antenna was soldered with the iris off-center $0.3 \mathrm{~mm}$ in the $x^{\prime \prime}$-direction (figure 3 ) from the center of the waveguide wa11. The patch was oriented so that the $y$-direction of the patch coincided with the $z^{\prime \prime}$-direction of the waveguide.

With a reflectionless termination placed after the antenna section, the input impedance of the waveguide-antenna section was measured, as plotted in figure B1. At the predicted resonant frequency of the antenna, $62.8 \mathrm{GHz}$, the normalized input impedance of the section was 0.87-j0.16.

The far-field power patterns were also observed at $62.8 \mathrm{GHz}$, as illustrated in figure B2. Gain of the antenna, as compared to the FXR standard gain horn, was $4.5 \mathrm{dBi}$. Undulations in the patterns are assumed to be due to reflectins from the test equipment. The sharp dip in the E-plane pattern at $0=-90^{\circ}$ is due to blockage from the waveguide circuit. Whereas for the transverse case the test equipment could be effectively screened by absorbing material below the antenna ground plane, for the longitudinal feed such screening is not so readily accomplished. Future work should be done using a waveguide feed circuit so designed as to eliminate such reflection problems.

The information presented here represents only preliminary results for the longitudinally fed antenna. These results do, however, indicate promise for this feed structure. Further comments concerning the direction of future study are made in the conclusion. 


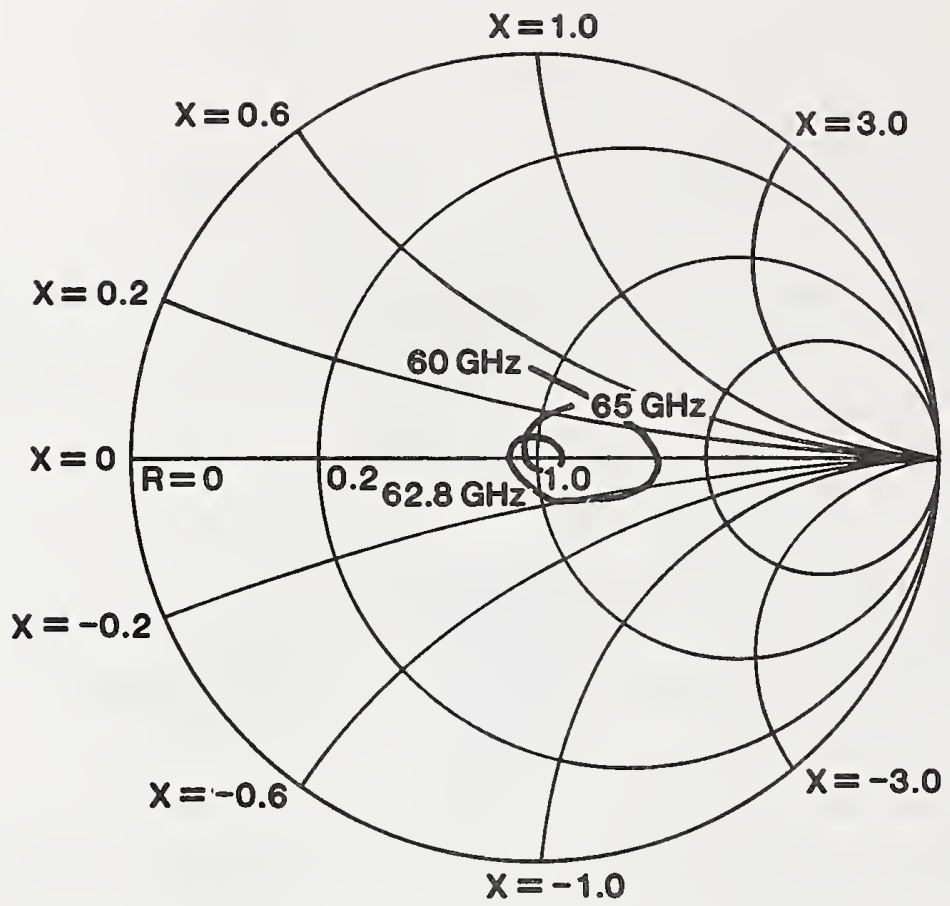

Figure B1. Input impedance of the longitudinally fed antenna.

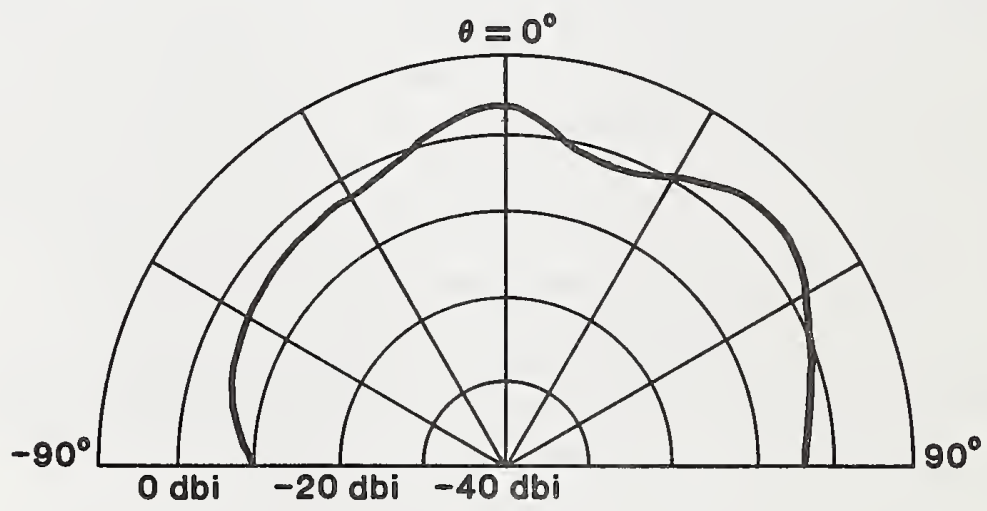

(a)

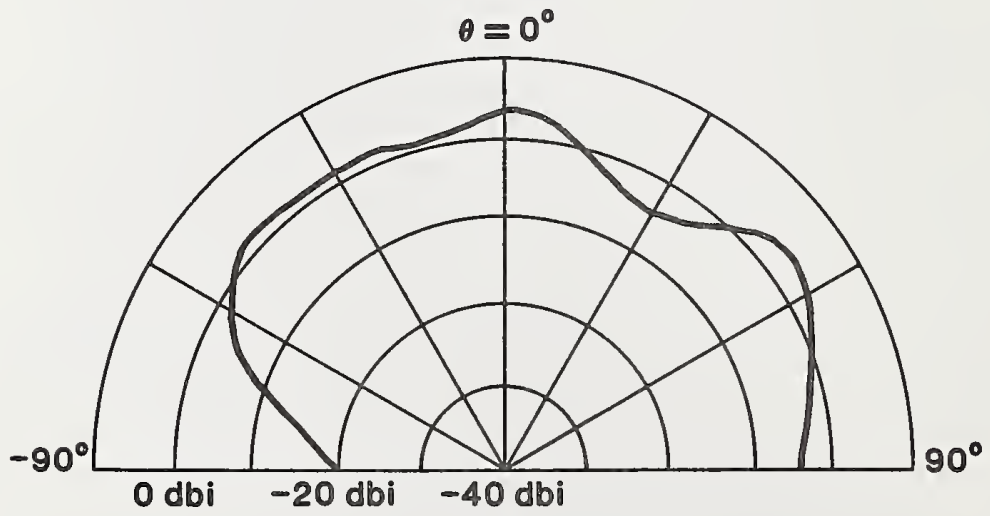

(b)

Figure B2. Far-field power pattern, longitudinally fed antenna, $62.8 \mathrm{GHz}$.

(a) H-plane.

(b) E-plane. 
U.S. DEPT. OF COMM.

BIBLIOGRAPHIC DATA

SHEET (See in structions)

4. TITLE AND SUBTITLE

1. PUBLICATION OR
REPORT NO.
NBS-TN-1063

2. Performing Organ. Report No.

3.

October 1983

The Characteristics of Iris-Fed Millimeterwave Rectangular Microstrip Patch Antennas

5. $A \cup T H O R(S)$

D. H. Greenlee, M. Kanda, D. C. Chang

6. PERFORMING ORGANIZATION (If joint or other than NBS, see instructions)

NATIONAL BUREAU OF STANDARDS

DEPARTMENT OF COMMERCE

WASHINGTON, D.C. 20234

9. SPONSORING ORGANIZATION NAME AND COMPLETE ADDRESS (Street, City, State, $\overline{\text { ZIP) }}$

7. Contract/Grant No.

Same (\#6)

10. SUPPLEMENTARY NOTES

[.] Document describes a computer program; SF-185, FIPS Software Summary, is attached.

11. ABSTRACT (A 200-word or less factual summary of most significant information. If document includes a significant bibliography or literature survey. mention it here)

The fabrication of various iris-fed millimeterwave rectangular microstrip patch antennas is described. A model is proposed to describe the iris-fed antenna. Irises ranging in size from 15 percent of the area of the patch to the fully open waveruide are used to couple energy into the antenna. Resonance of the antenna is obscrved to be insensitive to the size of the iris for irises up to 115 percent of the size of the patch. A study is also made of the relationship of coupling to the antenna as a function of the position of the iris with respect to the transverse plane of the waveguide, the iris always being centered with respect to the patch. In general, the antenna has a VSWR in the waveguide feed on the order of 5:1 at resonance, except for the fully open waveguide which gives rise to a VSWR of 2.9:1 at resonance. Farfield antellna power patterns are observed to be quite broad with $H$-plane beamwidths on the order of $130^{\circ}$. Maximum antenna gain is seen to be $4.5 \mathrm{dBi}$ with 3 dBi typical. An initial, study is made of the microstrip patch antenna fed from a longitudinal waveguide wall. Results indicate that this feed structure is likely to prove valuable for microstrip patch antennas with coupling at least as good as for the transverse-fed patch added to the possibility of feeding of multiple patches from a single wavceuide.

12. KEY WORDS (Six to twelve entries; alphabetical order: capitalize only proper names; and separate key words by semicolons) antenna gain; aperture coupling; cavity; half-power beamwidth; iris; microstrip; millimeterwave; patch antenna; power pattern.

13. AVAILABILITY

X Unlimited

$\square$ For Official Distribution. Do Not Release to NTIS

X] Order From Superintendent of Documents, U.S. Government Printing Office, Washington, D.C. 20402.

Order From National Technical Information Service (NTIS), Springfield, VA. 22161

14. NO. OF

PRINTED PAGES

50

15. Price

$\$ 4.00$ 




\section{NBS TECHNICAL PUBLICATIONS}

\section{PERIODICALS}

JOURNAL OF RESEARCH-The Journal of Research of the National Bureau of Standards reports NBS research and development in those disciplines of the physical and engineering sciences in which the Bureau is active. These include physics, chemistry, engineering, mathematics, and computer sciences. Papers cover a broad range of subjects, with major emphasis on measurement methodology and the basic technology underlying standardization. Also included from time to time are survey articles on topics closely related to the Bureau's technical and scientific programs. As a special service to subscribers each issue contains complete citations to all recent Bureau publications in both NBS and nonNBS media. Issued six times a year. Annual subscription: domestic $\$ 18$; foreign $\$ 22.50$. Single copy, $\$ 5.50$ domestic; $\$ 6.90$ foreign.

\section{NONPERIODICALS}

Monographs-Major contributions to the technical literature on various subjects related to the Bureau's scientific and technical activities.

Handbooks-Recommended codes of engineering and industrial practice (including safety codes) developed in cosperation with interested industries, professional organizations, and regulatory bodies.

Special Publications-Include proceedings of conferences sponsored by NBS, NBS annual reports, and other special publications appropriate to this grouping such as wall charts, pocket cards, and bibliographies.

Applied Mathematics Series-Mathematical tables, manuals, and studies of special interest to physicists, engineers, chemists, biologists, mathematicians, computer programmers, and others engaged in scientific and technical work.

National Standard Reference Data Series-Provides quantitative datid on the physical and chemical properties of materials, compiled from the world's literature and critically evaluated. Developed under a worldwide program coordinated by NBS under the authority of the National Standard Data Act (Public Law $90-396)$

NOTE: The principal publication outlet for the foregoing data is the Journal of Physical and Chemical Reference Data (JPCRD) published quarterly for NBS by the American Chemical Society (ACS) and the American Institute of Physics (AIP). Subscriptions, reprints, and supplements available from ACS, 1155 Sixteenth St., NW, Washington, DC 20056
Building Science Series-Disseminates technical information developed at the Bureau on building materials, components, systems, and whole structures. The series presents research results, test methods, and performance criteria related to the structural and environmental functions and the durability and safety characteristics of building elements and systems.

Technical Notes-Studies or reports which are complete in themselves but restrictive in their treatment of a subject. Analogous to monographs but not so comprehensive in scope or definitive in treatment of the subject area. Often serve as a vehicle for final reports of work performed at NBS under the sponsorship of other government agencies.

Voluntary Product Standards-Developed under procedures published by the Department of Commerce in Part 10. Title 15, of the Code of Federal Regulations. The standards establish nationally recognized requirements for products, and provide all concerned interests with a basis for common understanding of the characteristics of the products. NBS administers this program as a supplement to the activities of the private sector standardizing organizations.

Consumer Information Series-Practical information, based on NBS research and experience, covering areas of interest to the consumer. Easily understandable language and illustrations provide useful background knowledge for shopping in today's technological marketplace.

Order the above NBS publications from: Superintendent of Documents, Government Printing Office. Washington. DC 20402

Order the following NBS publications-FIPS and NBSIR's-from the National Technical Information Service, Springfield, VA 22161

Federal Information Processing Standards Publications (FIPS PUB)-Publications in this series collectively constitute the Federal Information Processing Standards Register. The Register serves as the official source of information in the Federal Government regarding standards issued by NBS pursuant to the Federal Property and Administrative Services Act of 1949 as amended, Public Law 89-306 (79 Stat. 1127), and as implemented by Executive Order 11717 (38 FR 12315, dated May 11, 1973) and Part 6 of Title 15 CFR (Code of Federal Regulations).

NBS Interagency Reports (NBSIR) - A special series of interim or final reports on work performed by NBS for outside sponsors (both government and non-government). In general, initial distribution is handled by the sponsor; public distribution is by the National Technical Information Service, Springfield, VA 22161, in paper copy or microfiche form. 
U.S. Department of Commerce

National Bureau of Standards

Washington, D.C. 20234

Official Business

Penalty for Private Use $\$ 300$

POSTAGE AND FEES PAID US. DEPARTMENT OF COMMERC COM-215

SPECIAL FOURTH-CLASS RATE BOOK 